\title{
Shaping and properties of thermoplastic scaffolds in tissue regeneration: The effect of thermal history on polymer crystallization, surface characteristics and cell fate
}

\author{
Andrea Roberto Calore ${ }^{1,2}$, Varun Srinivas ${ }^{2}$, Shivesh Anand ${ }^{1}$, Ane Albillos-Sanchez ${ }^{1}$, \\ Stan F. S. P. Looijmans ${ }^{3}$, Lambert C. A. van Breemen ${ }^{3}$, Carlos Mota ${ }^{1}$, Katrien Bernaerts ${ }^{2}$, \\ Jules A. W. Harings ${ }^{2, a)}$, Lorenzo Moroni ${ }^{1, a)}$ (D) \\ ${ }^{1}$ Complex Tissue Regeneration Department, MERLN Institute for Technology-Inspired Regenerative Medicine, Faculty of Health, Medicine and Life \\ Sciences, Maastricht University, Maastricht, The Netherlands \\ ${ }^{2}$ Aachen-Maastricht Institute for Biobased Materials (AMIBM), Faculty of Science and Engineering, Maastricht University, Urmonderbaan 22, \\ 6167 RD Geleen, The Netherlands \\ ${ }^{3}$ Polymer Technology, Eindhoven University of Technology, Eindhoven, The Netherlands \\ a) Address all correspondence to these authors. e-mails: jules.harings@maastrichtuniversity.nl; 1.moroni@maastrichtuniversity.nl
}

Received: 24 March 2021; accepted: 20 September 2021; published online: 21 October 2021

Thermoplastic semi-crystalline polymers are excellent candidates for tissue engineering scaffolds thanks to facile processing and tunable properties, employed in melt-based additive manufacturing. Control of crystallization and ultimate crystallinity during processing affect properties like surface stiffness and roughness. These in turn influence cell attachment, proliferation and differentiation. Surface stiffness and roughness are intertwined via crystallinity, but never studied independently. The targeted stiffness range is besides difficult to realize for a single thermoplastic. Via correlation of thermal history, crystallization and ultimate crystallinity of vitamin E plasticized poly(lactide), surface stiffness and roughness are decoupled, disclosing a range of surface mechanics of biological interest. In osteogenic environment, human mesenchymal stromal cells were more responsive to surface roughness than to surface stiffness. Cells were particularly influenced by overall crystal size distribution, not by average roughness. Absence of mold-imposed boundary constrains makes additive manufacturing ideal to spatially control crystallization and henceforward surface roughness of semi-crystalline thermoplastics.

\section{Introduction}

Additive manufacturing (AM) has emerged as a successful set of techniques in tissue engineering and regenerative medicine (TERM) for scaffold production as it gives full control over scaffold morphology. This feature is extremely important when manufacturing scaffolds for load bearing tissues, such as bone and cartilage, where the architecture plays an essential role in determining their mechanical performances $[1,2]$.

Melt-extrusion based techniques are a subset of AM methods that have become one of the most investigated strategies to produce scaffolds with thermoplastic polymers. This success is due to the relatively simple equipment needed and the lack of many requirements for the materials to be used, which only need to be thermoplastic in nature. The material, in the shape of a filament or pellets, is melted and extruded, by the application of pressure, through a nozzle. The AM unit moves in the $x-y$ plane to deposit a layer according to the desired pattern. By then shifting along the vertical axis, the following layers are deposited in the typical layer-by-layer manner, realizing scaffolds with tailored geometries [3].

In the framework of TERM, the flexibility in scaffold design and fabrication offered by AM is often coupled to the multipotency of human mesenchymal stromal cells (hMSCs). hMSCs have in fact gained a lot of interest in TERM thanks to their ability to differentiate, among others, towards the osteogenic and chondrogenic lineages. They can be cultured on scaffolds 
and their differentiation can be driven by several differentiation cues, to produce the tissue of interest. Cues can be nutrients and oxygen, soluble factors or substrate physico-chemical properties [4]. The choice of physical cues (e.g. material stiffness, surface roughness and topography) to instruct cellular behavior presents major benefits when compared to the use of biochemical stimuli alone, such as manufacturing costs, stability and a lower regulatory load when translated to the clinic [5].

For hard tissues, synthetic polymers represent a widespread choice when selecting the material for scaffold production. They can be designed and synthesized so that they can cause minimal or mild foreign body reaction, and they can be easily modified in terms of their physico-chemical properties when compared to natural-based counterparts. Additionally, many properties such as biodegradation rate, wettability and mechanical performances can be tailored by varying their chemical structure, architecture and molecular weight. In case of copolymers, swelling and protein adsorption can be influenced as well, by changing the copolymer ratio $[6,7]$.

Semi-crystalline polymers are often the materials of choice, because crystallization is known to enhance the mechanical performance of the final product. The crystalline phase tends to increase the stiffness and the strength of the material thanks to the strong interactions between adjacent chain segments. The amorphous regions are instead more effective in absorbing impact energy [8-11]. This is most evident at temperatures above the glass transition $\left(T_{\mathrm{g}}\right)$, where chain segments of the amorphous regions possesses conformational and translational motion, are more mobile and the modulus is affected mainly by the crystalline fraction [12].

However, the interest of tissue engineers for stiffness is not limited only to scaffold mechanical performances at the macro scale, i.e. product level. In fact, it has been shown that cell fate is influenced by the mechanics of the surrounding environment, beyond only soft hydrogels [13-16]. The link between substrate stiffness and cell fate has been revealed to be cell shape [17]: cells adhering on stiffer (i.e. with a Young's Modulus $E$ larger than $100 \mathrm{kPa}$ ) substrates tend to adopt a more spread conformation compared to those growing on softer (i.e. with $E<100 \mathrm{kPa}$ ) surfaces. In the case of stem cells, their shape affects their phenotype $[18,19]$. In particular, Chatterjee et al. [20] showed that hMSCs tend to secrete osteogenic markers when cultured on stiff substrates, while softer materials seem to induce a chondrogenic response [21]. Di Luca et al. [22] investigated the possibility of driving hMSCs fate with material properties in 3D scaffold fabricated by melt-based AM with no further post-processing. Scaffolds with a discrete gradient in surface stiffness were manufactured using three different materials in the attempt to mimic the osteochondral region, where the tissue stiffness ranges from $100 \mathrm{MPa}$ to beyond $1 \mathrm{GPa}$ for the bone compartment [23-25]. Besides being a promising approach from a TERM perspective, this strategy presents some limitations. From an engineering perspective, multi-material gradients require the use of multiple printheads or several loading and unloading cycles of different materials when a single printhead is used, making the process complicated and laborious. Additionally, variations in materials inherently imply variations in the chemistry of the materials used, which might further affect cell response but also hinder interdiffusion at the material interfaces that is based on miscibility and thus type of chemistry. Weak interfaces could result in poor mechanical properties once the whole scaffold is stressed macroscopically, in particular under shear, leading to implant premature failure.

The role of crystallinity in defining the final scaffold properties is not limited to affecting macroscopic stiffness. In the case of AM, the circumferential wall of the nozzle may template surface roughness, but volumetric constrains imposed by the surface roughness of molds do not exist. The crystals forming in proximity and at the surface will generate roughness, which is influenced by crystal size and density $[26,27]$. In the past, it has been reported that hMSCs fate could be driven by culturing the cells on substrates with different levels of roughness [28]. In particular, Faia-Torres et al. [29] found the existence of an optimal range of roughness for hMSCs osteogenic differentiation when cultured on poly ( $\varepsilon$-caprolactone) (PCL) membranes in dexamethasone-deprived osteogenic induction medium. Chen et al. [30] demonstrated that electrospun fibers with induced surface roughness supported osteogenic differentiation at high values (roughness average $\left(R_{\mathrm{a}}\right)=71 \pm 11 \mathrm{~nm}$ ) while promoted chondrogenesis at lower ones $\left(R_{\mathrm{a}}=14 \pm 2 \mathrm{~nm}\right)$. The mechanism by which cell fate is influenced seems to be deputed to the organization of the actin cytoskeleton associated with the microtopography of the substrate: surface features, as well as surface stiffness, affect cell adhesion and the resultant cell morphology, which is known to impact gene expression [29, 31-33]. Nevertheless, it is important to highlight how surface stiffness, chemistry and roughness are strongly intertwined and affected by crystallization. To our knowledge, the effects of surface stiffness and roughness on hMSCs fate have never been decoupled in previous studies and the potential influence of one while varying the other was not considered.

In melt-based AM, the crystallization process is governed mainly by thermal stresses and it is highly sensitive to the overall thermal history, especially when considering slowly crystallizing polymers like poly(L-lactide) (PLLA). Besides, thermal history in AM strategies deviates not only from conventional thermoplastic processing/shaping technologies, but also per additively assembled layer or voxel in three dimensional space. To understand the final material and object properties, it is paramount to note that the deposited material is constantly undergoing thermal stresses along the whole manufacturing process, even after solidification. Following the deposition, the material is 
often kept above its $T_{\mathrm{g}}$ to promote interfacial diffusion, bonding and crystallization to achieve enhanced mechanical properties. Additionally, because of the raster deposition pattern, the nozzle periodically returns in the proximity of previously deposited material, whether within or on top of a specific layer, and reheats the polymer. Srinivas et al. [34] showed that a spatial variations in crystallinity could be found along the building direction (2D) and may exist even in 3D, resulting in inhomogeneous mechanical properties over the object through controlled in gradients, for example, if the thermal management of the printing process is understood.

Considering the effect of crystallization on key material properties such as stiffness and roughness, thermal management appears to be a critical variable when manufacturing scaffolds with thermoplastic polymers. By accurately tuning it, researchers could influence cell behavior by just applying the proper thermal history to the polymer, without having to embed additives in the polymer matrix $[35,36]$, post-process the scaffold $[37,38]$ or use multiple materials [22].

When thermoplastics are kept above their $T_{\mathrm{g}}$, for a given material chemistry, their elastic modulus typically ranges from 0.5 to $1000 \mathrm{MPa}$ dependent on their crystallinity [12]. As previously mentioned, PLLA is a slowly crystallizing material that allows for fine-tuning of its crystallinity, with a $T_{\mathrm{g}}$ of around $55-60{ }^{\circ} \mathrm{C}$. In this work, we propose the plasticization of PLLA to achieve stiffness variations in the order of magnitude of the osteochondral region at body temperature, ranging from 100-1000 $\mathrm{MPa}[23,28,39,40]$, without relying on multiple materials securing interfacial binding and macroscopic mechanical integrity. In order to control surfaces stiffness within the osteochondral range, we then investigate the effect of typical thermal treatments in melt-based AM on surface stiffness or roughness of thin films, separating the two properties. An illustration of the followed workflow can be found in Fig. 1. We show how these surface properties are affected just by varying the thermal history of the material, as in melt-based AM. Stiffness and roughness were then quantified by surface indentation and profilometry. Eventually, the potential influence of these parameters on hMSCs osteogenic differentiation was explored.

\section{Results}

\section{Material selection}

A suitable candidate material was required to have $T_{\mathrm{c}}$ and $T_{\mathrm{g}}$, respectively, above and below body temperature. Polymer materials with a $T_{\mathrm{g}}$ below body temperature enable the control of (surface) stiffness by means of crystallinity. However, materials with reduced crystallinity, i.e. made via incomplete crystallization, are thermodynamically instable and tend to crystallize if sufficient conformational and translational motion is administered by for example heat. This process is known as cold crystallization and may not occur at body temperature (body conditions) to secure the suppressed crystallinity and associated stiffness. The thermoplastic candidates that comply to the above physiochemical criteria and evaluated in this

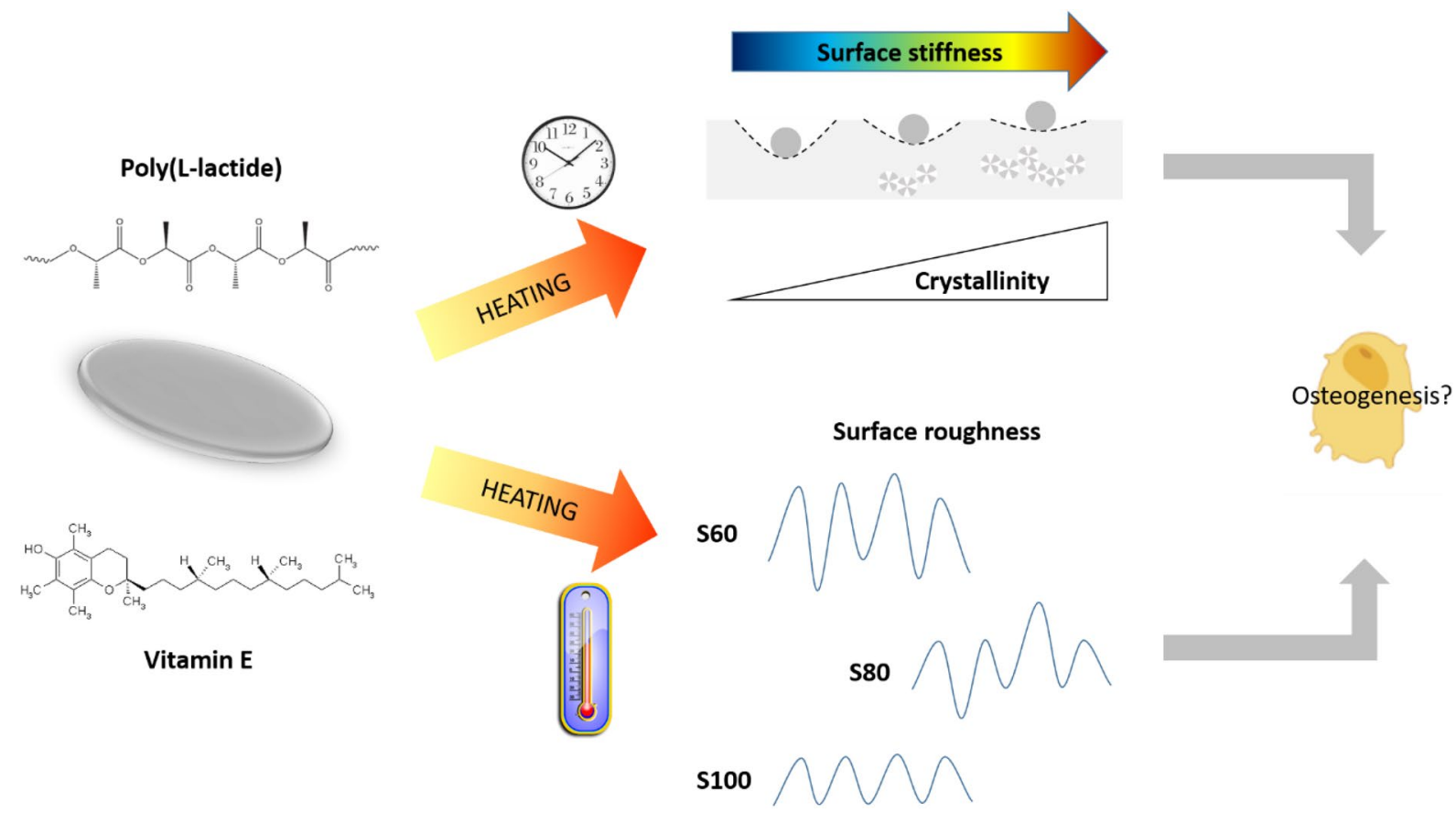

Figure 1: Schematic of the workflow followed to develop the current study. 
study are poly( $\varepsilon$-caprolactone) (PCL), poly(dioxanone) (PDO), poly(hydroxybutyrate-co-hydroxyvalerate) (PHBV), and a vitamin E plasticized poly(L-lactide) (PLLA). Due to its known fast crystallization kinetics and low glass transition temperature $\left(\sim-60^{\circ} \mathrm{C}\right)$ [41], the thermal behavior of PCL was studied in a fast-scanning chip calorimeter (flash DSC). The PCL sample was melted at $90^{\circ} \mathrm{C}$, quenched by cooling with varying cooling rates and heated again to detect potential cold crystallization as a signature of suppressed crystallinity and its thermal stability. The thermograms in Fig. 2A show cold crystallization peak for cooling rates higher than $1.0 \mathrm{E} 4{ }^{\circ} \mathrm{C} / \mathrm{min}$ at around $-30^{\circ} \mathrm{C}$, with the onset at around $-44^{\circ} \mathrm{C}$. This makes this material effectively unusable for the purpose of the study, as it would crystallize even before reaching body temperature.

As PLLA exhibits those slow crystallization kinetics needed to have full control over the process, it was considered as a promising candidate. Nevertheless, the $T_{\mathrm{g}}$ higher than body temperature would make it a glassy material at $37^{\circ} \mathrm{C}$, where changes in crystallinity would result only in slight variations in stiffness. To reduce the $T_{\mathrm{g}}$, the material was plasticized with vitamin $\mathrm{E}$. The choice was based on the fact that vitamin $\mathrm{E}$ is biocompatible and relatively hydrophobic [42], reducing the
A

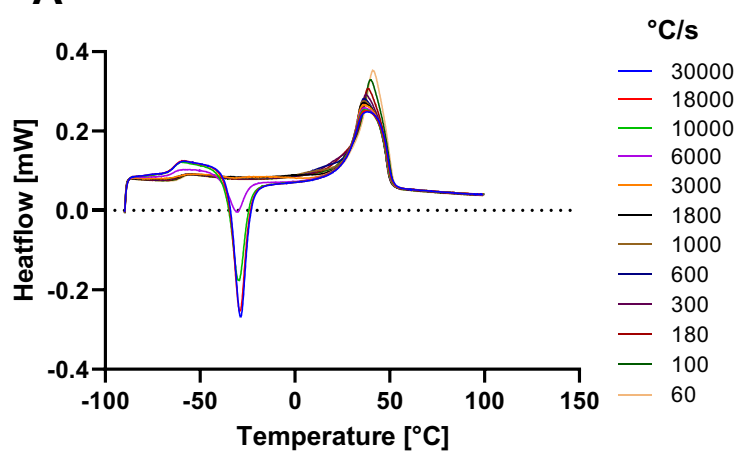

C

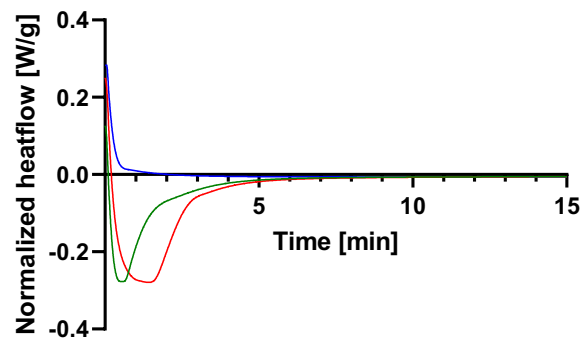

- PDO - PHBV - PLLA/VE18
B

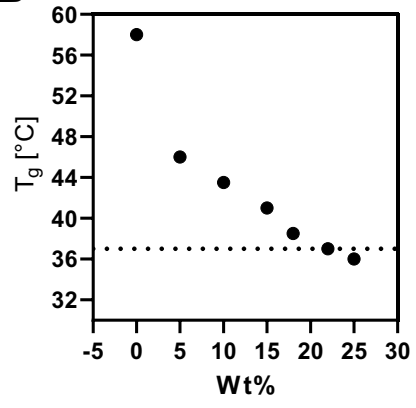

D

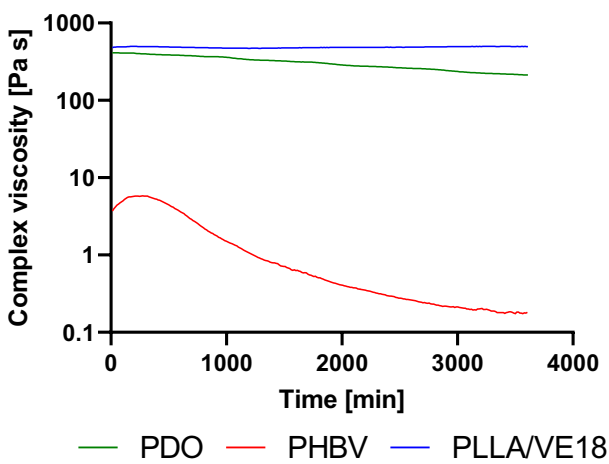

E

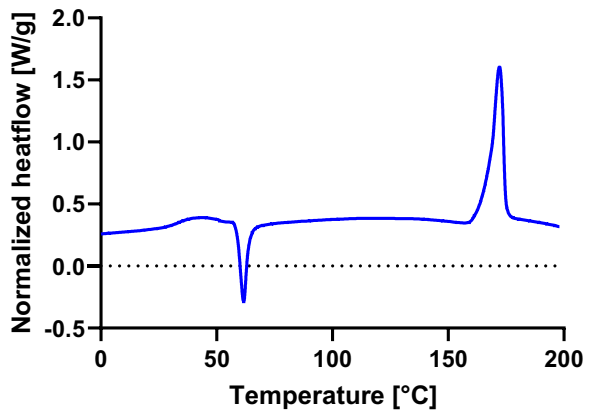

Figure 2: (A) Fast-scanning chip calorimetry thermograms upon heating of $\mathrm{PCL}$ with fixed heating rate but made by varying cooling rate ranging from $6.0 \mathrm{E} 1$ to $3.0 \mathrm{E} 4{ }^{\circ} \mathrm{C} / \mathrm{min}$ (legend), showing a cold crystallization well below room temperature for samples with incomplete crystallization, i.e. cooled faster than $1.0 \mathrm{E} 4{ }^{\circ} \mathrm{C} / \mathrm{min}$. (B) The effect of increasing weight percentage VE on the glass transition temperature ( $T_{\mathrm{g}}$ ) of the PLLA/VE blends. (C) Isothermal behavior of PDO, PHBV and PLLA/VE1 8 at $37^{\circ} \mathrm{C}$. Only the PLLA/VE18 blend did not show any crystallization at body temperature for the time of the test. (D) Melt stability of PDO, PHBV and PLLA/VE18 at $190^{\circ} \mathrm{C}$ expressed at complex viscosity over time. (D) (E) DSC thermogram of PLLA/ VE18. Measurements were repeated at least three times. 
risk of leaching out that would cause uncontrolled properties over time. A series of blends were prepared and their $T_{\mathrm{g}}$ was measured via DSC. As can be observed in Fig. 2B, the glass transition temperature decreased with increasing concentration of VE concentration and, in particular, the blend with $18 \%$ showed a $T_{\mathrm{g}}$ close to $37^{\circ} \mathrm{C}$, making it a good candidate for the study. This particular blend was then tested for cold crystallization at body temperature and melt stability, as for the other material candidates. In the isothermal crystallization study at $37^{\circ} \mathrm{C}$ using the conventional DSC, PDO and PHBV fully crystallized in less than 10 min (Fig. 2C). Additionally, PDO and PHBV showed a gradual decrease in complex viscosity over time in the melt rheology analysis (Fig. 2D). Only the PLLA/VE18 blend exhibited a stable behavior. In particular, Fig. 2C, D (blue lines) show that no cold crystallization or viscosity drop happened at the test temperatures during the measurement time.

Figure 2E shows the DSC heating trace of PLLA/VE18 from an amorphous state, recorded at a heating rate of $10^{\circ} \mathrm{C} / \mathrm{min}$. It can be seen that the cold crystallization peak starts at $60^{\circ} \mathrm{C}$ and finishes at around $105^{\circ} \mathrm{C}$. The annealing temperature of $60^{\circ} \mathrm{C}$ was chosen for the surface stiffness study, being the lowest temperature at which crystallization could take place. This would allow high control over the crystallization process with respect to higher temperatures. Temperatures of 60,80 and $100{ }^{\circ} \mathrm{C}$ were selected for the annealing of the films for the surface roughness study.

\section{Surface stiffness}

It is well-known that polymers upon melt processing cannot be purely crystalline in nature and are in fact semi-crystalline. In this work, we define $\mathrm{X}_{\mathrm{t}} 100$ as the maximum attainable crystallinity in crystallization from the melt. Amorphous films $\left(\mathrm{X}_{\mathrm{t}} 0\right)$ were prepared and the crystallization kinetics were evaluated by means of isothermal DSC at $60^{\circ} \mathrm{C}$. As it can be seen from Fig. $3 \mathrm{~A}, 50 \%$ relative crystallinity $\left(\mathrm{X}_{\mathrm{t}} 50\right)$ was achieved in less than $2 \mathrm{~min}$ while roughly $8 \mathrm{~min}$ are necessary for a fully crystallized $\left(\mathrm{X}_{\mathrm{t}} 100\right)$ sample. From these results, $50 \%\left(\mathrm{X}_{\mathrm{t}} 50\right)$ and $100 \%$ $\left(\mathrm{X}_{\mathrm{t}} 100\right)$ crystalline samples were produced by annealing at $60^{\circ} \mathrm{C}$ for the indicated time and then rapidly quenched to prevent further crystallization. DSC measurements showed that $\mathrm{X}_{\mathrm{t}} 50$ films exhibited an absolute crystallinity of $21 \%$ while $\mathrm{X}_{\mathrm{t}} 100$ of $52 \%$ (data in Supporting Information, Fig. S1). Their mechanical properties were evaluated under torsion by DMTA to measure their shear modulus G'. Already at room temperature, the modulus followed the expected increasing trend with crystallinity, with the amorphous, 50 and $100 \%$ crystalline samples showing G'values of 396, 653 and $891 \mathrm{MPa}$, respectively. Compared to $\mathrm{X}_{\mathrm{t}} 0$, these correspond to an increase in stiffness of 65 and $125 \%$ for $\mathrm{X}_{\mathrm{t}} 50$ and $\mathrm{X}_{\mathrm{t}} 100$. This difference became even more marked at body temperature, where the $50 \%$ crystalline sample exhibited a surface stiffness of $465 \mathrm{MPa}$ while full crystallization gave a G' value of $788 \mathrm{MPa}$, respectively, 104 and $246 \%$ higher than the amorphous sample (228 MPa).

As the bulk material properties measured via DMTA are not always representative of the surface stiffness, indentation measurements were performed. The force was recorded as a function of displacement during the loading and unloading cycles on samples kept at 23 and $37^{\circ} \mathrm{C}$. The contact stiffness $S$ was calculated using the method of Pharr et al. [43], according to which $S$ is given by the initial slope of the unloading curve. As in the case of torsional DMTA, Fig. 3D and Fig. 3E show, respectively, how both $S$ and the maximum force $\left(F_{\max }\right)$ increased with crystallinity, at both tested temperatures. The 50 and $100 \%$ samples showed contact stiffness respectively 17 and $30 \%$ higher than the amorphous samples, at room temperature. Instead, at $37^{\circ} \mathrm{C}$, these differences raised to 143 and $207 \%$. The maximum force followed the same trend: at $23^{\circ} \mathrm{C}, \mathrm{X}_{\mathrm{t}} 50$ and $\mathrm{X}_{\mathrm{t}} 100$ showed values 17 and $24 \%$ higher than the amorphous film, which increased to 192 and $261 \%$ at body temperature.

\section{Surface roughness}

Surface topography was characterized by laser scanning microscopy (see figure in Supporting Information) and arithmetic mean height of the surface $\left(R_{\mathrm{a}}\right)$, the root mean square height of the surface $\left(R_{\mathrm{q}}\right)$, the maximum height of the surface $\left(R_{\mathrm{z}}\right)$ and texture aspect ratio (Str) were measured. Data in Table 1 show general lower averages for films annealed at $100{ }^{\circ} \mathrm{C}$. Interestingly, S60 and S80 films show a broad distribution for all the parameters evaluated while annealing at $100{ }^{\circ} \mathrm{C}$ gave surface features of limited variability. This is reflected in particular in the higher values of texture aspect ratio for $\mathrm{S} 100$, which is a measure of the uniformity of the surface texture. Nonetheless, no statistically significant difference was observed across conditions.

\section{Contact angle}

To confirm that the annealing did not alter the surface composition, measurements of contact angle by means of the sessile drop technique were performed. As can be seen in Fig. 4A, left, there is no statistically relevant difference among films with different crystallinity fraction. The same result was found for films annealed at different temperatures, as shown in Fig. 4A, right.

\section{Cell studies}

To evaluate the cytotoxicity of the VE, films were placed in transwell on top of well containing a monolayer of MG-63 cells. Cells cultured with VE films were able to grow as shown by the increasing DNA amount over time (Fig. 4B). The number of cells was higher for conditions cultured with VE films 


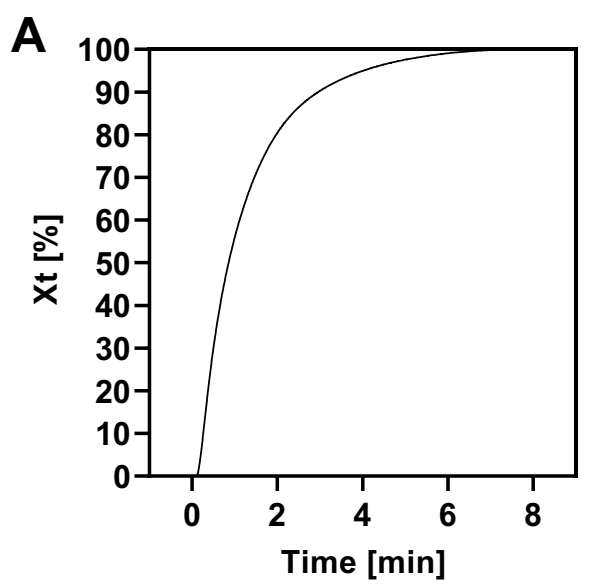

B

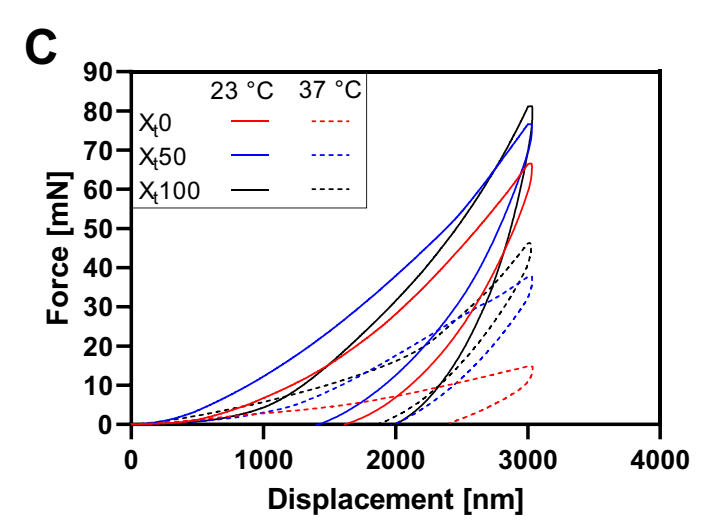

D

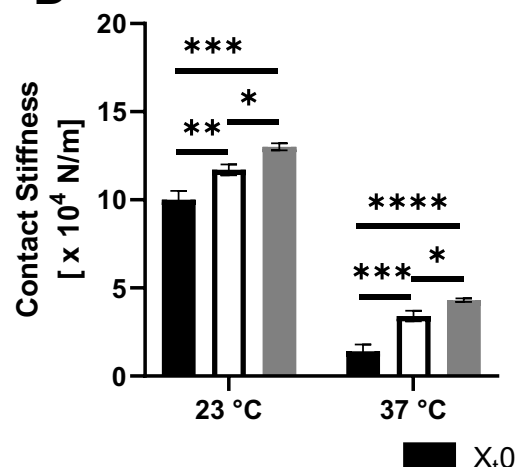

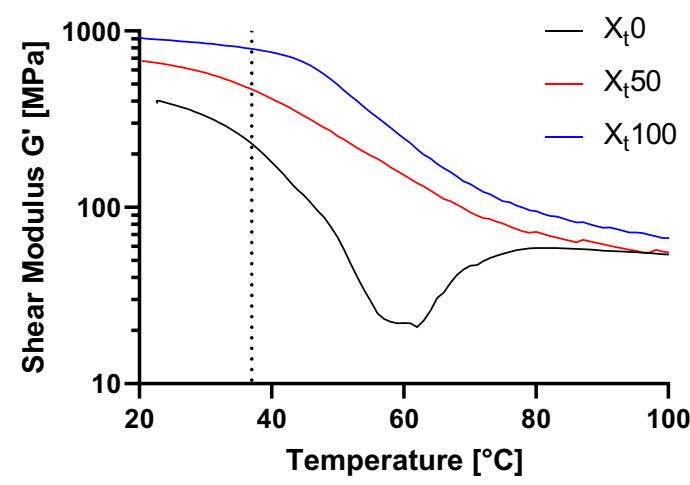

$\mathbf{E}$

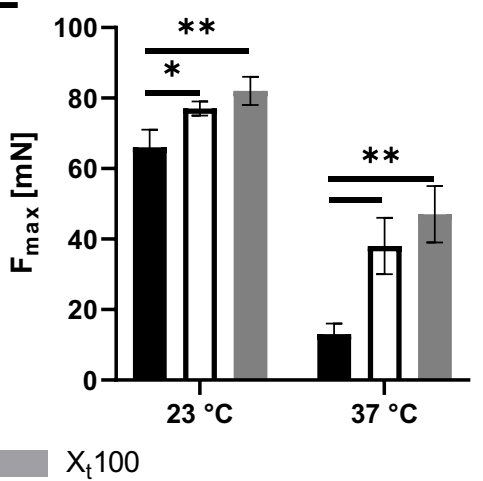

Figure 3: (A) Relative crystallinity plotted as function of time for isothermal crystallization of PLLA/VE 18 at $60^{\circ} \mathrm{C}$. After less than 8 min, full crystallinity is achieved. (B) Dynamic shear modulus of PLLA/VE18 at different crystallinity fractions as a function of temperature. The dashed line indicates $37^{\circ} \mathrm{C}$, where a clear difference in bulk shear modulus can be seen. (C) Force-displacement diagram from indentation tests on films with different crystallinities, at room and body temperature. It can be seen how the trend from bulk mechanical testing is followed by surface mechanics as well. (D) Contact stiffness $(S)$ and $(E)$ maximum force $\left(F_{\text {max }}\right)$ for amorphous, Xt50 and Xt100 crystalline samples measured by indentation at $23^{\circ} \mathrm{C}$ and $37^{\circ} \mathrm{C}$. Data in (D-E) is presented as mean \pm standard deviation; $n=3$. Statistically significant differences are marked with ${ }^{*} p<0.05,{ }^{* *} p<0.01$ or ${ }^{* * *} p<0.001$ when comparing the effect of different conditions.

compared to controls and they also exhibited higher proliferation. However, cells showed a constant metabolic activity over 3 days, which was lower than the controls at the last day of culture.

In an attempt to overcome VE hydrophobicity, plasma treatment and collagen coating were tested as methods to maximize the seeding efficiency (Fig. 4C). The two strategies did not gave significant differences in the number of cells per film but the amount of attached cells was significantly lower than tissue culture plates for both treatments. However, the metabolic activity per cell seemed higher for cells cultured on film even though not statistically different. Considering that plasma treatment 
TABLE 1: Parameters describing the roughness of the analyzed surfaces: arithmetic mean height of the surface $\left(R_{\mathrm{a}}\right)$, root mean square height of the surface $\left(R_{\mathrm{q}}\right)$, maximum height of the surface $\left(R_{\mathrm{z}}\right)$ and texture aspect ratio (Str).

\begin{tabular}{llllc}
\hline \hline Sample & $R_{\mathrm{a}}(\mu \mathrm{m})$ & \multicolumn{1}{c}{$R_{\mathrm{q}}(\mu \mathrm{m})$} & $R_{\mathrm{z}}(\mu \mathrm{m})$ & \multicolumn{1}{c}{ Str } \\
\hline S60 & $0.63 \pm 0.47$ & $1280 \pm 626.9$ & $6.96 \pm 2.09$ & $0.45 \pm 0.31$ \\
S80 & $0.64 \pm 0.73$ & $1058 \pm 853.5$ & $7.05 \pm 5.8$ & $0.43 \pm 0.27$ \\
S100 & $0.31 \pm 0.01$ & $651.1 \pm 106$ & $3.72 \pm 0.86$ & $0.8 \pm 0.07$ \\
\hline \hline
\end{tabular}

There is no significant difference between the samples.

could etch polymeric surfaces $[44,45]$ and that collagen coating should not mask the surface stiffness nor the surface roughness to cells $[14,16]$, the latter was chosen as surface treatment method for further studies.

\section{Surface stiffness}

The range of achievable surface stiffness during the deposition process was tested for osteogenic effects on hMSCs. Cells were cultured on amorphous, $50 \%$ and $100 \%$ crystalline films for 28 days, in basic or osteogenic conditions, after 7 days of proliferation. At day 7, cells seemed to have proliferated homogenously on all films (Fig. 5, left), besides on the amorphous substrates in PM where the DNA content was higher than the other films in the same medium, but also than the corresponding sample in DM. They also showed to be metabolically active, with those cultured on amorphous and ( $\left.\mathrm{X}_{\mathrm{t}} 50\right)$ films in osteogenic conditions displaying higher activity than their counterparts in PM. Additionally, the amorphous and $\mathrm{X}_{\mathrm{t}} 50$ samples in DM gave a higher reading than the maximum crystalline one. At day 28, the DNA increase was relatively low when compared to values obtained for day 7. The amorphous and $\mathrm{X}_{\mathrm{t}} 50$ films in PM showing higher DNA content than their counterparts in DM (Fig. 5, right). Furthermore, amorphous films gave higher cell amount than $\mathrm{X}_{\mathrm{t}} 50$ sample. Similarly to what observed for day 7, cells on day 21 were significantly more metabolically active in DM than those in basic conditions. Cells also maintained a more rounded morphology in PM and a more spread morphology in DM at both time points (Figs. S3, S5).

ALP expression at both time points (Fig. 6, left) for all conditions was higher for DM than in PM, which did not show any increase in ALP values over the culture. In PM, $X_{t} 50$ showed the lowest ALP secretion, but the opposite trend was visible at day 28. In osteogenic conditions, the amorphous films seems to have induced a higher ALP secretion after 7 days, while at day 28 the two different crystallinity conditions supported higher ALP activity.

Figure 6 (middle) shows also that osteopontin (OPN) production at day 7 in basic medium followed an increasing trend with stiffness, albeit not statistically significant, while in DM
$\mathrm{X}_{\mathrm{t}} 50$ resulted in significantly greater secretion. Nevertheless, no significant differences could be seen between the two culture environments. Instead, at day 28 the OPN secretion was higher in PM, with $\mathrm{X}_{\mathrm{t}} 50$ showing the highest value. OCN levels in Fig. 6 (right) seemed to be decreasing over the culture, resulting in the highest values in DM, at both time points. In particular, cells cultured on the half-crystallized film secreted the most OCN.

\section{Surface roughness}

Potential osteogenic effects on hMSCs were evaluated also by culturing cells on fully crystalized films in non-confined conditions, so to allow crystals on the surface to freely develop and generate roughness. DNA data showed that cells proliferated in all conditions and both media, with films in basic conditions giving higher cell amount at both time points (Fig. 7, top). Interestingly, the fold change over the culture period was roughly the same for both culture environments. Cells were also metabolically active (Fig. 7, bottom), with DM cultures supporting enhanced activity at both 7 and 28 days. The expression of all three osteogenic markers was generally higher in osteogenic environment (Fig. 8). ALP secretion increased over time, while osteopontin and osteocalcin production decreased. ALP values at day 28 in DM seemed to increase with increasing annealing temperature. Interestingly, the difference between S100 and each of the two other conditions was more significant than the difference between S60 and S80. The secretion of OPN at day 28 in the osteogenic environment showed a very marked peak for S60, while $\mathrm{S} 80$ and $\mathrm{S} 100$ were comparable to PM culture conditions. Films annealed at $80 \mathrm{C}$ supported enhanced osteogenic activity for all the three markers in DM at day 7, but for OCN only at day 28. Cells had a generally spread morphology in both PM and DM culture conditions and at both time points (Figs. 9, S4).

\section{Discussion}

The main aim of the current study was to investigate the polymer crystallization directed evolution of polymer surface stiffness and surface roughness during additive manufacturing and their potential osteogenic effects on mesenchymal stromal cells. The effect of these two features has been extensively explored, although most studies that focused on the influence of material stiffness on cell differentiation employed hydrogels $[13,16,46,47]$. Some pioneering work with semi-crystalline polymers was done by Hendrikson et al. [14]. They showed that hMSCs were able to sense the difference in stiffness between scaffolds made of different $M_{\mathrm{w}}$ PCL: cells cultured on softer PCL resulted in a higher hypertrophic chondrogenic differentiation. Di Luca et al. [22] fabricated scaffolds with a gradient in stiffness by sequentially using a poly(ethylene oxide terephthalate)/poly(butylene terephthalate) (PEOT/ PBT) copolymer, PCL and PLA and noted that the softer 


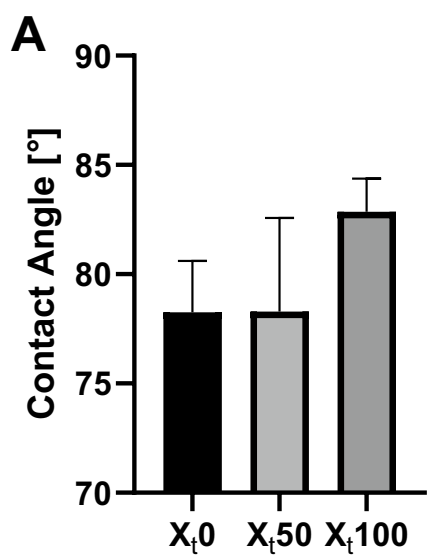

B

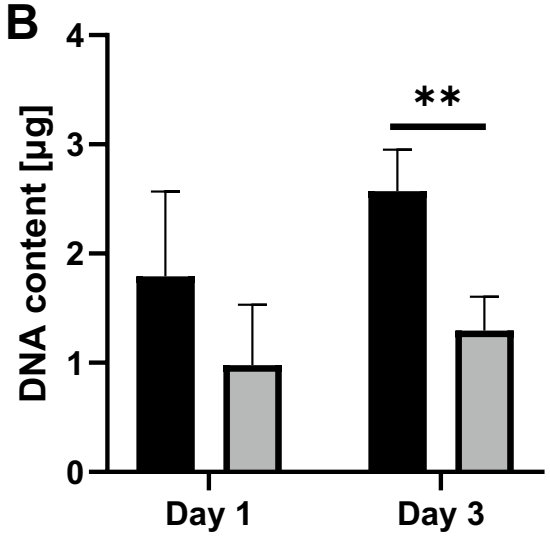

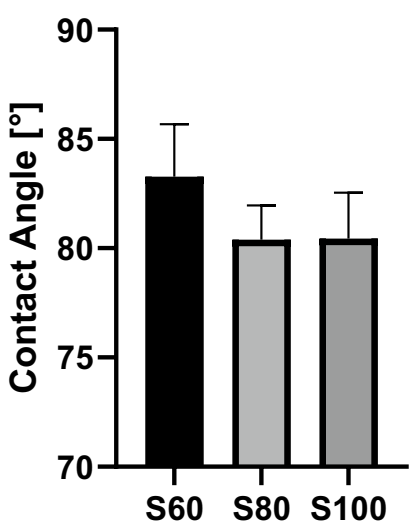

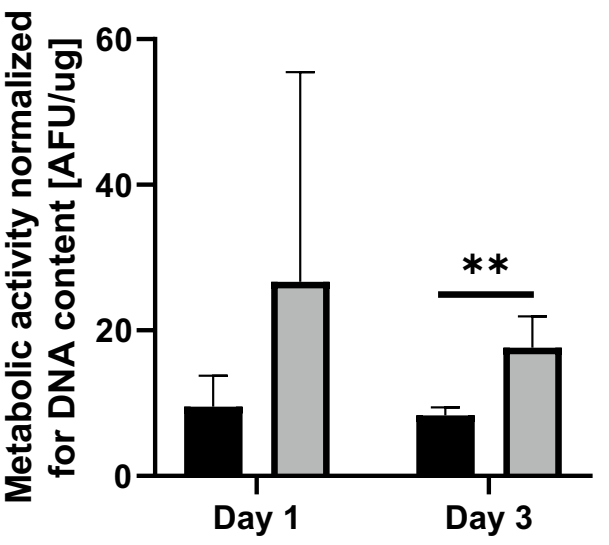

Day 1

Controls
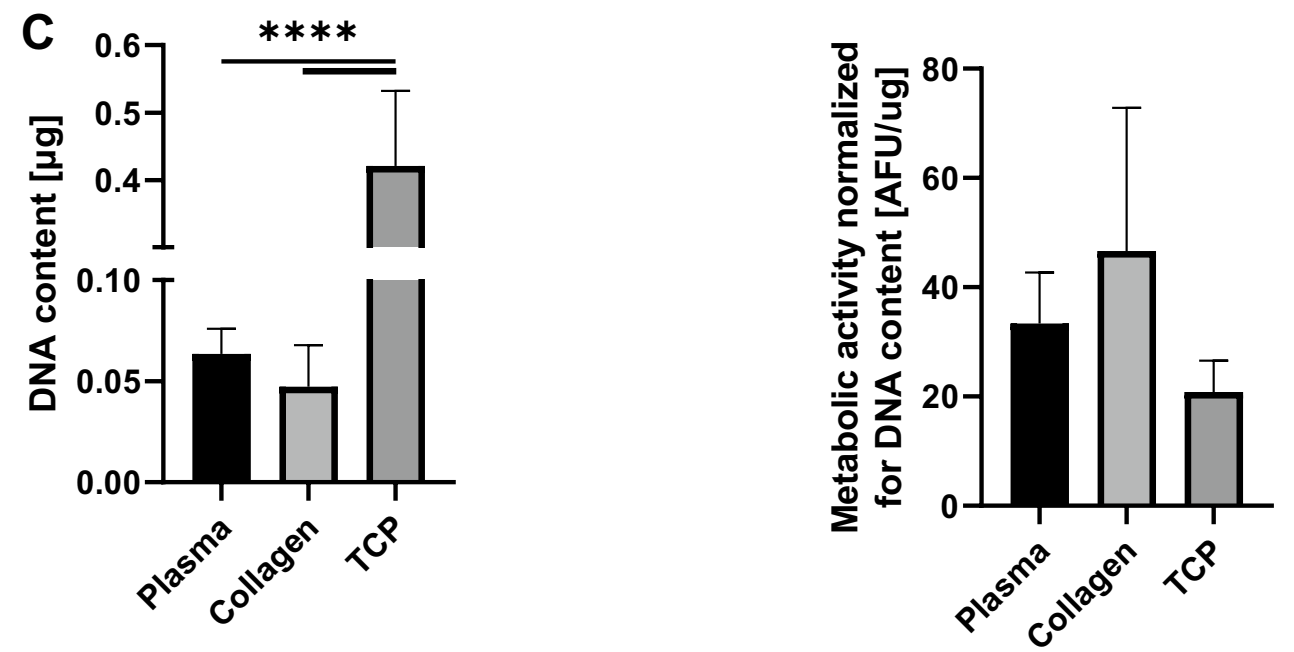

Figure 4: (A) Left: water contact angle of films with different crystallinities. Despite higher mean angle for maximum crystalline films, no significant differences could be seen. Right: water contact angle of films annealed at different temperatures. Despite higher mean angle for maximum crystalline films, no significant differences could be observed. (B) DNA quantification and metabolic activity of MG-63 cells cultured on tissue culture well plates (TCWP) in which transwells with (samples) or without (controls) PLLA/VE18 films were placed. At day 3, cells cultured with films were significantly more than on control plates, but they showed lower metabolic activity per cell. (C) DNA quantification and metabolic activity of MG-63 cells seeded on TCWP and collagen or plasma treated films, after $24 \mathrm{~h}$. Films showed a significantly lower seeding efficiency but a comparable metabolic activity per cell. Statistically significant differences are marked with ${ }^{*} p<0.05,{ }^{* *} p<0.01$ or ${ }^{* * *} p<0.001$ when comparing the effect of different conditions. Data is presented as mean \pm standard deviation; $n=3$. 
7 DAYS
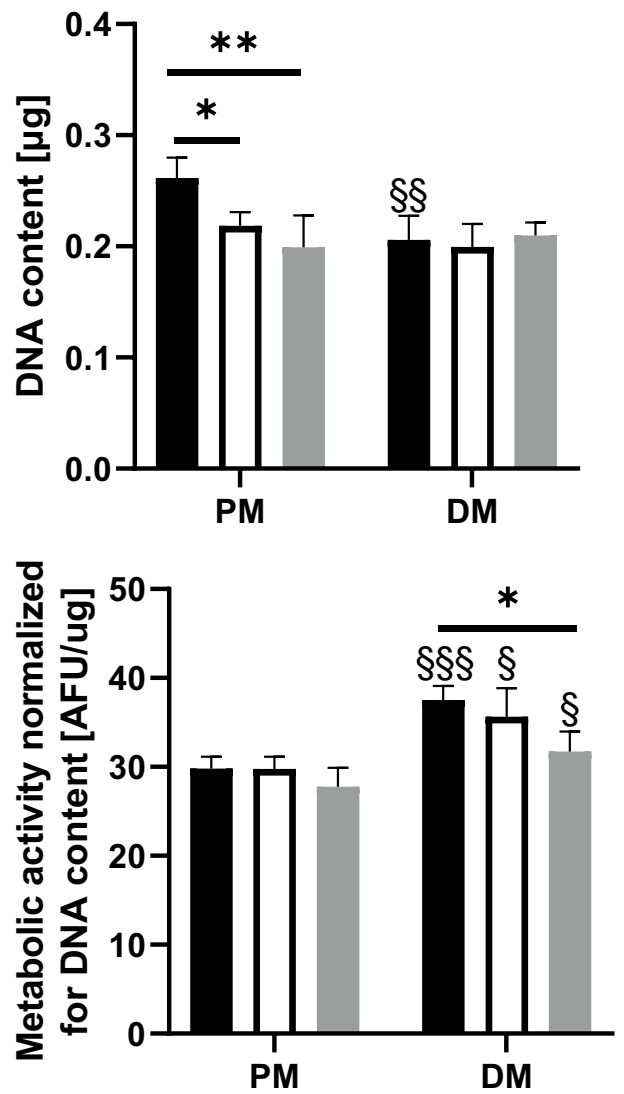

28 DAYS
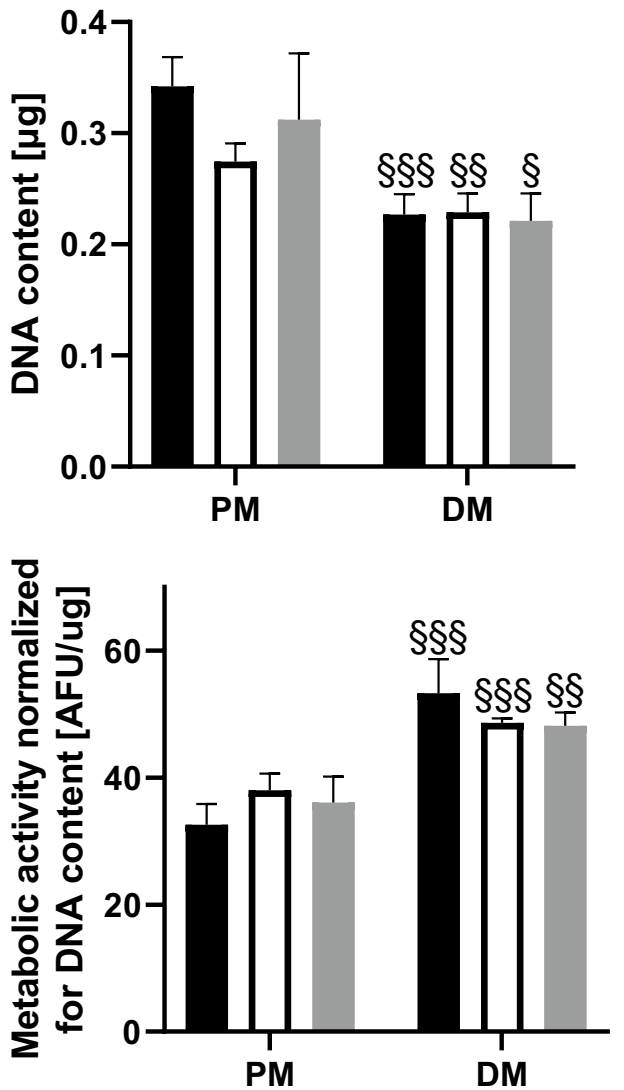

- $\mathrm{X}_{\mathrm{t}} 0$ 口 $\mathrm{X}_{\mathrm{t}} 50 \backsim \mathrm{X}_{\mathrm{t}} 100$

\begin{abstract}
Figure 5: Proliferation and metabolic activity of the human mesenchymal stromal cells (hMSCs) at day 7 (left column) and day 28 (right column), in either proliferation medium (PM) or differentiation medium (DM) conditions (after 7 days in PM), on films with varying crystallinity and surface stiffness. Statistically significant differences are marked with ${ }^{*} p<0.05,{ }^{* *} p<0.01$ or ${ }^{* * *} p<0.001$ when comparing the effect of different surface stiffness on cells cultured in the same cell medium and ${ }^{\S} p<0.05,{ }^{\S \S} p<0.01$ or ${ }^{\S \S} p<0.001$ when comparing the effect of different media on cells cultured on films with the same surface stiffness. Data is presented as mean \pm standard deviation; $n=3$.
\end{abstract}

PEOT/PBT showed the highest ALP activity of seeded hMSCs after seven days under osteogenic conditions. On the other hand, the influence of crystallinity-induced surface roughness on cell differentiation has not been much investigated to our knowledge. Most studies either generated surface roughness by other means [29-31] or evaluated other effects (e.g. cell proliferation) than differentiation $[27,48]$. Nevertheless, despite we cannot exclude also the effect of material chemistry, surface stiffness and roughness are deeply intertwined as both are influenced by the development of crystallinity. To our knowledge, these two properties have never been really decoupled. The same properties were herein investigated separately for the induction of osteogenesis on hMSCs.

The first part of the study focused on finding a proper semicrystalline polymer whose crystallization could be finely controlled to tune its properties at the temperature of interest. The material was expected to have a $T_{\mathrm{g}}$ below $37^{\circ} \mathrm{C}$ so that the polymer could exhibit a rubbery behavior at body temperature and a sufficiently low crystallization rate to control its stiffness by means of crystallinity fraction. Additionally, the absence of cold crystallization at $37^{\circ} \mathrm{C}$ was necessary to provide constant properties over time, and stable melt processability was needed to allow the preservation of material properties during processing. Several polymers were taken into consideration because of their $T_{\mathrm{g}}$ below body temperature. These were poly( $\varepsilon$-caprolactone) (PCL), poly(dioxanone) (PDO) and poly(hydroxybutyrate-cohydroxyvalerate) (PHBV). PCL is a well-known thermoplastic polymer widely used in tissue engineering and in AM for scaffold production thanks to its easy processing and stable thermal properties [41]. PDO has been used in sutures and offers a shorter biodegradation time than PCL [49]. PHBV is a copolymer whose degradation rate and crystallinity can be tailored 

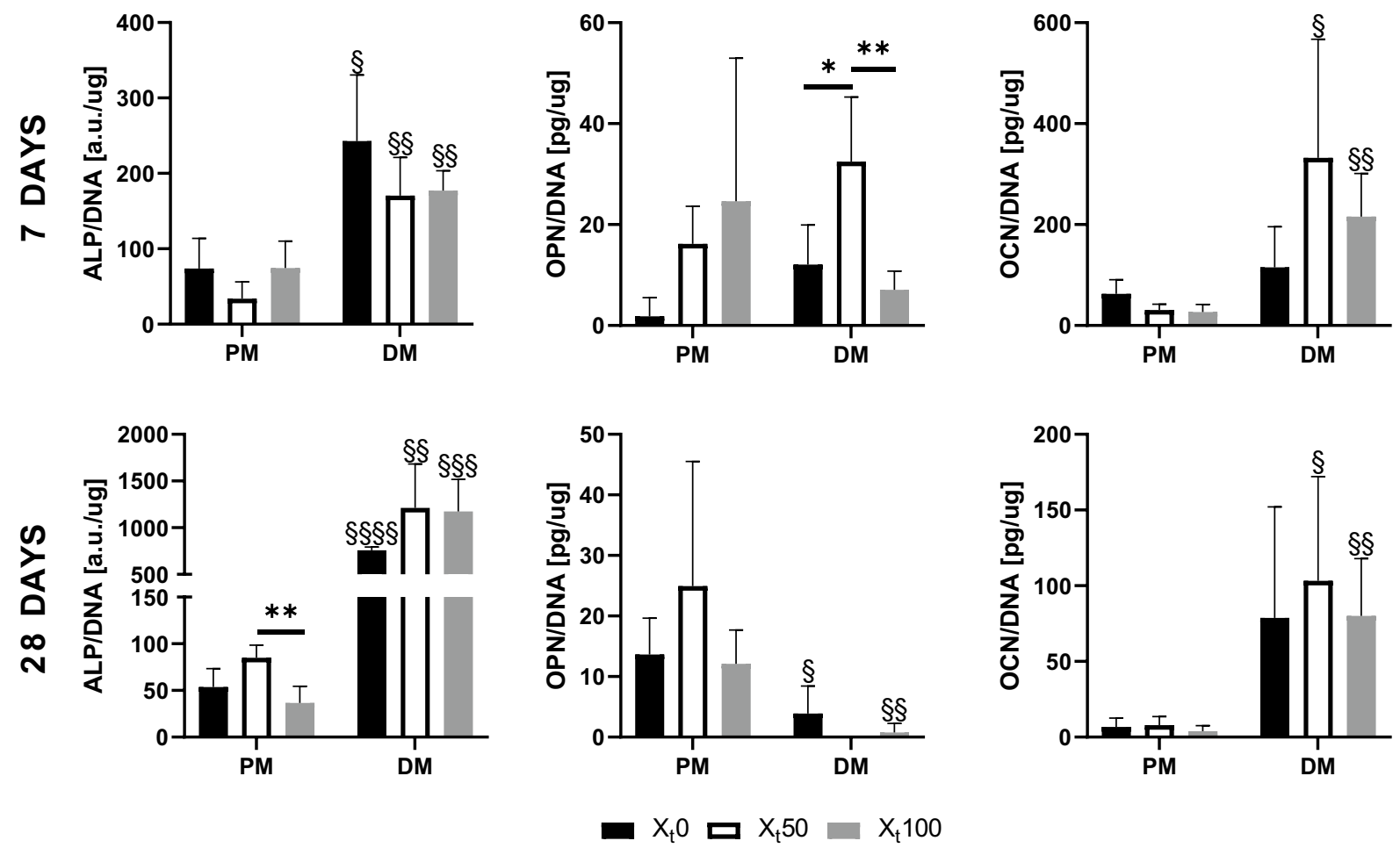

Figure 6: Expression of osteogenic markers from the human mesenchymal stromal cells (hMSCs) at day 7 (top row) and day 28 (bottom row), in either proliferation medium (PM) or differentiation medium (DM) conditions (after 7 days in proliferation medium), on films with varying crystallinity and surface stiffness. Statistically significant differences are marked with ${ }^{*} p<0.05,{ }^{* *} p<0.01$ or ${ }^{* * *} p<0.001$ when comparing the effect of different surface stiffness on cells cultured in the same cell medium and ${ }^{\S} p<0.05,{ }^{\$ \S} p<0.01$ or ${ }^{\S \S \S} p<0.001$ when comparing the effect of different media on cells cultured on films with the same surface stiffness. Data is presented as mean \pm standard deviation; $n=3$.

by varying the copolymerization ratio [50]. Fast-scanning chip calorimetry showed that PCL exhibited the cold crystallization peak at around $-30{ }^{\circ} \mathrm{C}$, making the material crystallize to its maximum extent at room and body temperature. Since this would give no margin to control the material's crystallinity and therefore its stiffness, PCL was discarded. In isothermal studies, PDO and PHBV both showed cold-crystallization at $37^{\circ} \mathrm{C}$ over time. This characteristic hinders their use as scaffold materials as the product properties would not be constant over time under body conditions. Additionally, PHBV displayed very poor thermal stability in rheological tests, affecting the material properties during melt-processing. Due to its slow crystallization kinetics and control in crystallinity via cooling rate, PLLA was considered as potential alternative. As its $T_{\mathrm{g}}$ is around $58^{\circ} \mathrm{C}$, we decided to plasticize it with vitamin $\mathrm{E}$ ( $\alpha$-tocopherol). This selection was based on the fact that vitamin $\mathrm{E}$ is biocompatible and relatively hydrophobic, reducing the risk of leaching out in aqueous body conditions and causing changes in material properties. As seen Fig. 2B, the addition of VE successfully increases the mobility of the conformational and local translational polymer chains with a resulting decrease in the glass transition temperature proportional to the VE content. As an excessively low $T_{\mathrm{g}}$ could result in cold crystallization over time and consequent unstable mechanical properties [51], the blend with $18 \mathrm{wt} \%$ was chosen for further studies.

Apart from decoupling the development of the two surface properties for the first time, we intended to explore the possibility of providing a material system that allows for production of scaffolds with predictable and controllable surface stiffness or surface roughness, given the appropriate thermal history, without recurring to multi-material systems [22]. The clear advantages are several: (i) easy processing as only one material would be used; (ii) enhanced mechanical performance due to better interlayer adhesion; (iii) possibility of tuning surface stiffness and/or roughness without changes in surface chemistry or energy. Given the known influence of surface stiffness and roughness on cell activity, and in particular on hMSCs differentiation, we wanted to explore whether the achievable ranges of properties with this material system would affect cell response. Subjecting this material system to annealing conditions typical of melt-based AM, we controlled the crystallization process in an attempt to produce films with a wide range of surface stiffness but also to explore the effects of crystallinity development on surface roughness. By changing crystallization time in confined conditions, films with different crystallinity fractions and therefore surface stiffness were obtained, while maintaining a 


\section{DAYS}
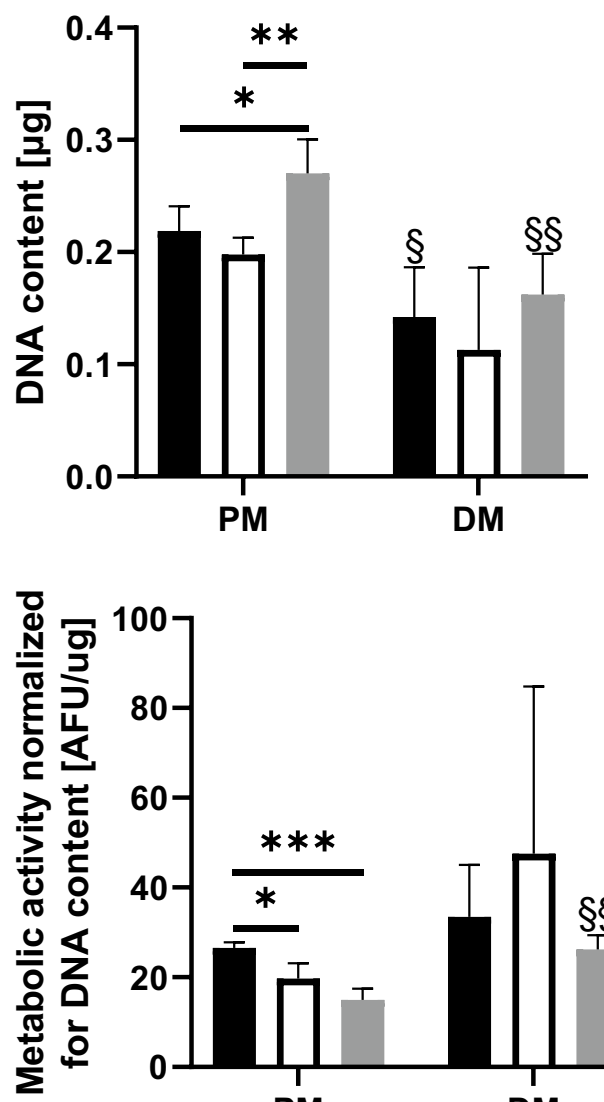

PM
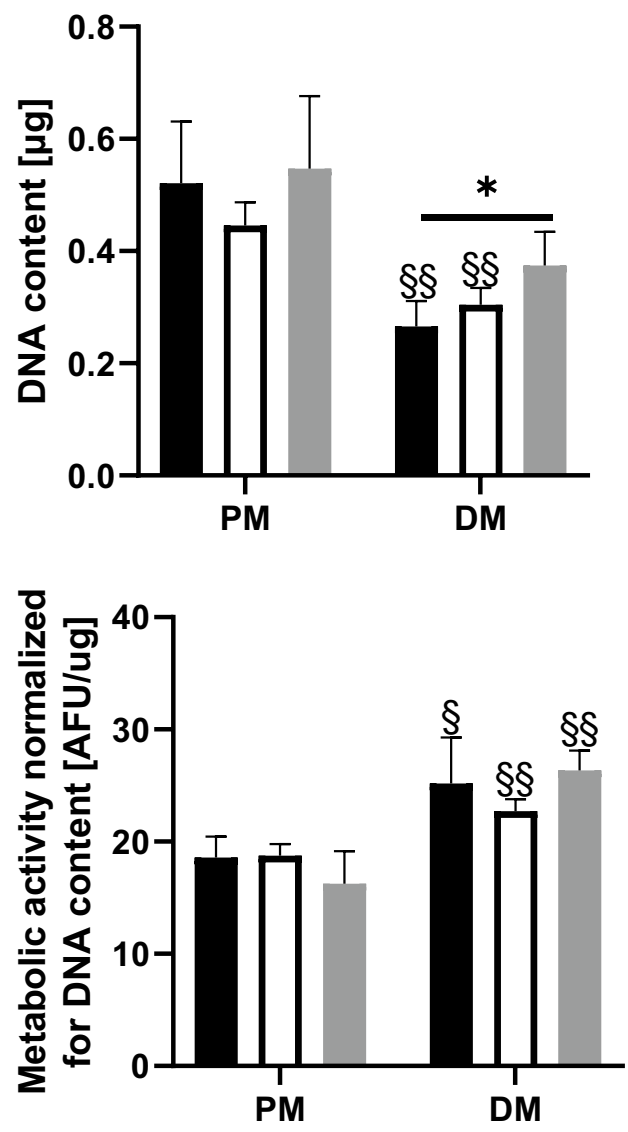

S100

Figure 7: Proliferation and metabolic activity of the human mesenchymal stromal cells (hMSCs) at day 7 (left column) and day 28 (right column), in either proliferation medium (PM) or mineralization medium (DM) conditions (after 7 days in proliferation medium), on films annealed at different temperatures. Statistically significant differences are marked with ${ }^{*} p<0.05,{ }^{* *} p<0.01$ or ${ }^{* * *} p<0.001$ when comparing the effect of different surface roughness on cells cultured in the same cell medium and ${ }^{\S} p<0.05,{ }^{\S \S} p<0.01$ or ${ }^{\S \S} p<0.001$ when comparing the effect of different media on cells cultured on films with the same surface roughness. Data is presented as mean \pm standard deviation; $n=3$.

constant roughness. On the other hand, fully crystallizing films in non-confined condition, allowed us to affect the surface roughness of the films while reaching maximum stiffness. When annealed for different times, the material crystallinity fraction could be controlled and a wide range of bulk stiffness at body temperature could be obtained, as confirmed by DMTA data. In torsional experiments, the steeper drop in moduli for the amorphous sample is due to the fact the in semi-crystalline polymers the crystals are responsible for network formation and loadbearing at temperatures above the $T_{\mathrm{g}}$ [52]. Upon heating towards higher temperatures, the initial decrease in moduli for the amorphous sample is followed by an increase. This can be explained by the process of cold crystallization above the glass transition temperature, which does not happen for the sample with maximum crystallinity. This confirms that maximum crystallinity was achieved. As the bulk properties as measured by DMTA are not always representative for what happens at the surface, the local surface stiffness was investigated by indentation, which confirmed the results obtained in tensile and torsional testing. The described results confirm that the plasticization process allowed us to reduce PLLA $T_{\mathrm{g}}$ so that to have a material in the rubbery plateau at body temperature. This allowed us to obtain a substantial variation in surface stiffness at body temperature by changing the crystallinity fraction. In particular, the achieved range is within the observed values in the osteochondral interface, making this material system a valid choice as thermoplastic polymer for AM of gradient scaffolds.

Bearing in mind that crystallization does not have an influence on surface stiffness only but affects its roughness as well, films were annealed until achievement of full crystallinity, at 60,80 and $100{ }^{\circ} \mathrm{C}$. This approach was meant to induce the same surface stiffness to all the samples while investigating 

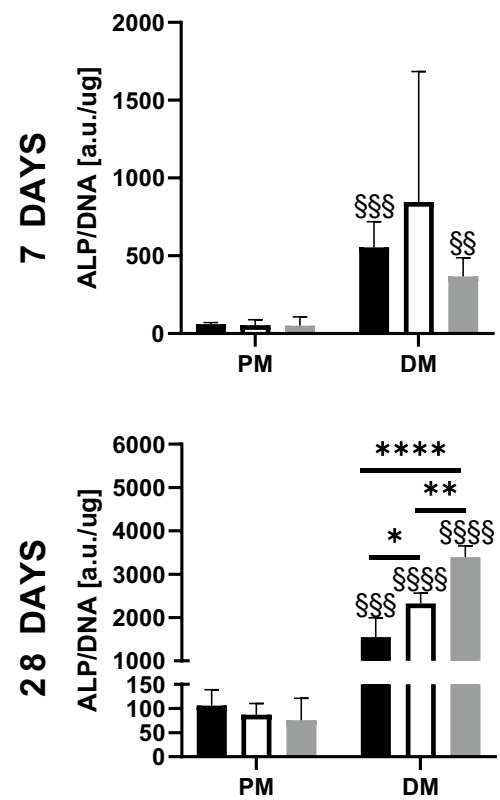
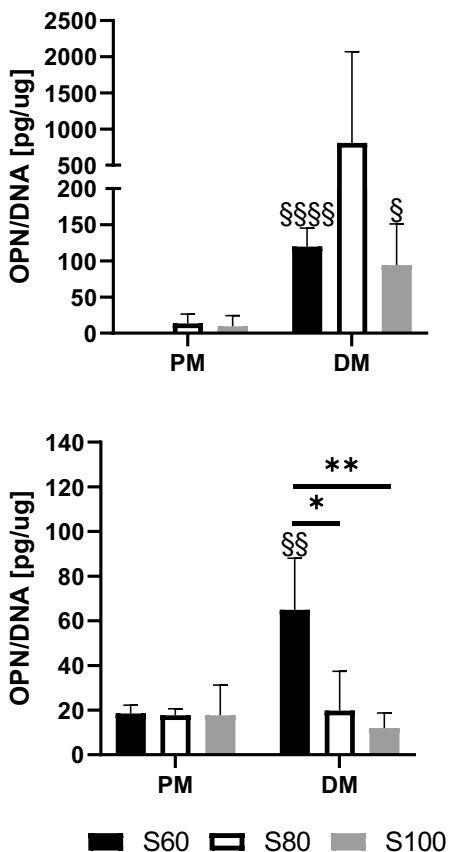
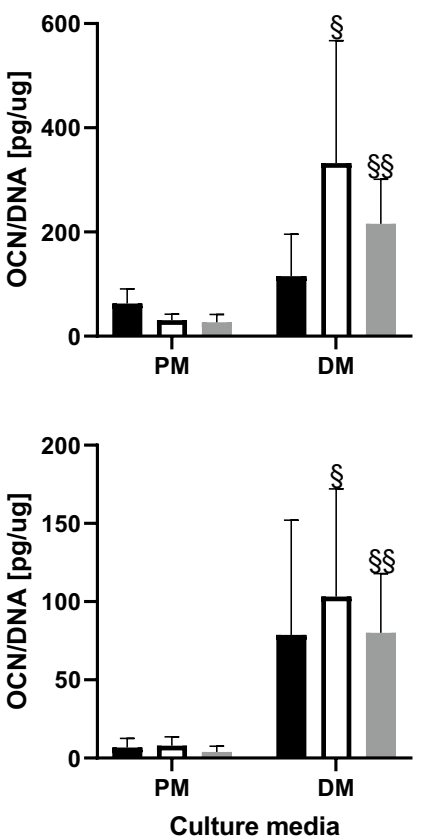

Figure 8: Expression of osteogenic markers from the human mesenchymal stromal cells (hMSCs) at day 7 (top row) and day 28 (bottom row), in either proliferation medium (PM) or differentiation medium (DM) conditions (after 7 days in PM), on films annealed at different temperatures. Statistically significant differences are marked with ${ }^{*} p<0.05,{ }^{* *} p<0.01$ or ${ }^{* * *} p<0.001$ when comparing the effect of different surface roughness on cells cultured in the same cell medium and ${ }^{\S} p<0.05,{ }^{\S \S} p<0.01$ or ${ }^{\S \S \S} p<0.001$ when comparing the effect of different media on cells cultured on films with the same surface roughness. Data is presented as mean \pm standard deviation; $n=3$.

the effect of possible printing bed or chamber temperatures on the roughness of the fibers. Data showed that the samples all exhibited comparable mean roughness values but with different size distribution. In terms of average, the result is in line with the findings of Tsuji et al. [53], who studied the effect of annealing after quenching on crystal properties of PLLA films. They reported that the spherulite nucleation density or radius seemed to be unchanged with the annealing temperature, in their studied range $\left(100-160^{\circ} \mathrm{C}\right)$. In this study, the evaluated range was $60-100^{\circ} \mathrm{C}$. However, in our opinion, the wide size distribution of $\mathrm{S} 60$ and $\mathrm{S} 80$ films may still be explained by the competition between heating, and nucleation and growth kinetics. As described by Li [54], the heating process can be modelled with the lumped-capacity approach whereas the Biot number is lower than 0.1. Given a film with radius of $25 \mathrm{~mm}$ and thickness of $0.4 \mathrm{~mm}$, a convection coefficient $h=50-100 \mathrm{~W} /\left(\mathrm{m}^{2}{ }^{\circ} \mathrm{C}\right)$ and thermal conductivity $k=0.2 \mathrm{~W} /\left(\mathrm{m}{ }^{\circ} \mathrm{C}\right)$ [55], we can estimate a Biot number in the range 0.049-0.098. This allows us to assume uniform temperature distribution throughout the horizontal section and thus to simplify the film heating process into a onedimensional transient heat transfer model with a convection cooling term:

$$
\frac{\partial T}{\partial t}=\frac{k}{\rho C} \frac{\partial^{2} T}{\partial z^{2}}-\frac{h P}{\rho \mathrm{CA}}\left(T-T_{\mathrm{amb}}\right)
$$

where $z$ is the coordinate along the film thickness, $t$ is time, $T(z, t)$ is the temperature, $T_{\mathrm{amb}}$ is the environmental temperature, $\rho$ is the density, $C$ is the heat capacity. The solution of the equation with the appropriate boundary and initial conditions shows that the time to reach the annealing temperature is inversely proportional to the temperature itself. Samples annealed at $100^{\circ} \mathrm{C}$ reached the annealing temperature from $\mathrm{RT}$ sooner than the two others did. We hypothesize that heating of the sample happened faster than the start of nucleation. In fact, there exists a time to reach the steady state population of crystal embryos or nuclei, called the induction time [56]. This is a function of temperature and follows a concave parabolic trend [57]. It is possible that the time to heat to $100{ }^{\circ} \mathrm{C}$ was shorter than the induction time. Therefore nuclei would form all the same time and thus spherulites would grow homogeneously within the same time window. This is called athermal nucleation. For S60 and S80, the time taken to reach the annealing temperature was probably longer than the induction time, allowing stable nuclei to form at different temperatures along the process. In the meanwhile, these nuclei would grow into crystals over time. Crystals formed at earlier stages had more time to grow while crystals formed later grew to a lesser extent (thermal nucleation).

Different crystallinities did not result in different water contact angles. This is in line with the study of (A. Park and Cima 1996), where it was found that the water advancing 

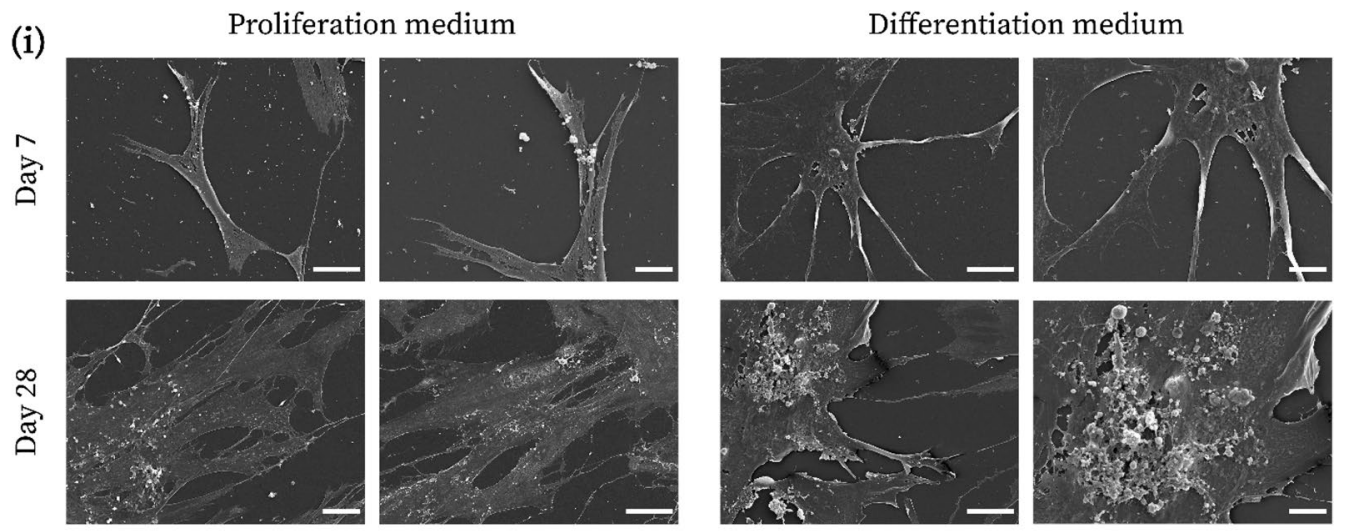

(ii)
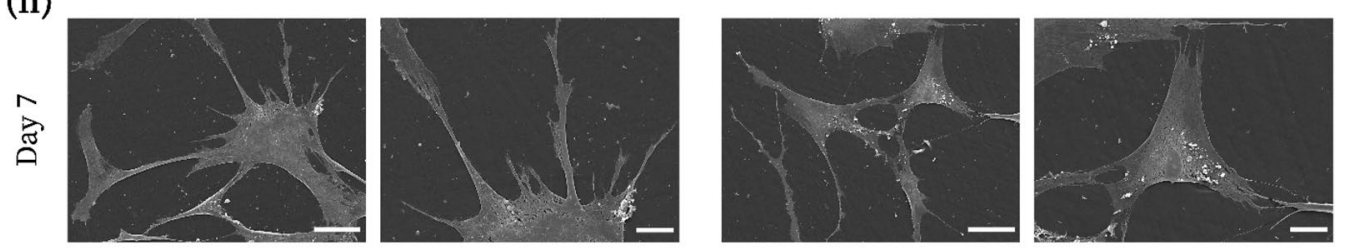

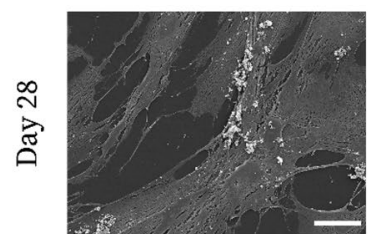

LM

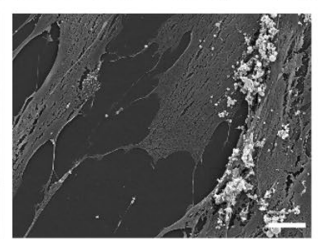

$\mathrm{HM}$

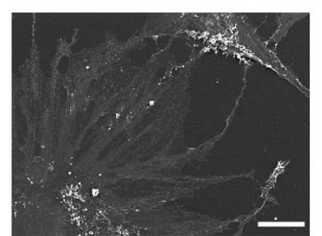

LM

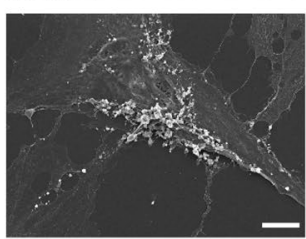

HM

Figure 9: Cell morphology as observed under scanning electron microscopy at day 7 and day 28 for the hMSCs cultured on (i) S80 and (ii) S100 films. The micrographs revealed no visual differences between the cells cultured on different films. Scale bars: low magnification (LM) $50 \mu \mathrm{m}$; high magnification (HM) $20 \mu \mathrm{m}$.

contact angle for amorphous and maximum crystalline PLLA films were identical. No differences in contact angle suggest that the changes in bulk properties due to crystallization did not affect the surface wettability of the films. Different surface wettability would affect how water molecules and proteins would adsorb on the surface, thus influencing cell adhesion and consequently morphology and activity (Wei et al. 2009). Films for the roughness study did not show different contact angles as well. According to Wolanksy and Marmur [58], the contact angle measured experimentally on the macroscopic scale (apparent contact angle) describes an average for the entire contact line, which might differ from the actual local contact angle on rough surfaces. The high standard deviations of S60 and S80 state that there is a wide absolute variation in crystal size, which averages out to the same value for all three sample types. Assuming a random distribution of these crystals on the surface, we hypothesize that on the macroscopic scale their contributions counterbalance, giving a similar apparent contact angle for all the three sample types. Finally, it is important to note that, in both studies, the water contact angle of around $80^{\circ}$ was at the border of the ideal region identified by Tamada et al. [59] for optimal cell attachment.
Vitamin $\mathrm{E}$ is known to be bioactive and it has already been used for TE purposes in past studies [60,61]. Nevertheless, here PLLA was plasticized with a relatively high concentration that might have induced toxic effects to cells. For this purpose, a transwell study was run. Cells cultured where films were placed, showed as much proliferation as the controls, meaning that the presence of VE did not induce any cytotoxic effect. However, PrestoBlue $^{\mathrm{m} m}$ results indicated lower metabolism, in particular at day 3. This could be a sign of the potential excessive plasticizer on the surface slowly diffusing in the cell medium, which could have affected cell activity over time. VE is in fact relatively hydrophobic and its dissolution even in small amounts takes time. The results were considered positive nonetheless, as possible excessive plasticizer diffusion from the surface is counterbalanced in longer cultures with regular medium refresh while here the same medium was used for the whole experiment. Hence, the decrease in metabolic activity could be likely due to the exhaustion of cell nutrients over the first 3 days of culture, thus excluding any potential toxicity associated to VE.

Vitamin E hydrophobicity was expected to influence cell attachment as well. A cell seeding efficiency study was run, comparing the performance of two of the most common used 
surface treatments to increase cell adhesion, plasma modification and collagen coating. The two strategies led to comparable amounts of cells on the films, which were significantly lower than TCP controls. This was most likely due to excessive vitamin molecules on the surface, which might have hindered the effectiveness of the surface treatments when compared to plain TCP. In selecting the appropriate treatment method, it was considered that the action of plasma might etch the polymer surface, affecting the crystallization-induced surface roughness. On the other hand, collagen is a semi-flexible polymer with a persistence length of $15 \mathrm{~nm}[62,63]$, which forms fibrils of 200-2500 nm in diameter [64]. Given these elements and the hydration induced softening in aqueous conditions, we postulated that the collagen molecules would not excessively mask the surface roughness of the films annealed at different temperatures and we chose this as a surface treatment method.

We successfully produced polymer films where we decoupled the effects of crystallinity on surface roughness and surface stiffness. We first achieved a wide range of surface stiffness and quantified the effect of annealing on surface roughness, and then assessed their impact on the osteogenic differentiation of hMSCs. Cells cultured on films with varying stiffness showed limited proliferation over time, which could be the result of poor affinity with the substrates. This could be due to the relatively high water contact angle or due the smoothness of the surface given by the silicon wafers $[65,66]$. Nevertheless, they were metabolically active, although differences could be seen between the two media used. Cells in basic environment proliferated more. But showed lower metabolic activity per cell than their counterparts in DM. PrestoBlue ${ }^{\mathrm{TN}}$ assay is based on the reduction of resazurin to resorufin by mitochondrial activity; [67] and [68] noted that differentiation often leads to an increase in mitochondrial oxidation. This suggests that cells in DM might already be differentiating at the early time point.

From the ALP profile in PM at day 28, it can be hypothesized that $\mathrm{X}_{\mathrm{t}} 50 \%$ might trigger osteogenic differentiation more than the other conditions in PM, as it is the only conditions showing an increase over time. Considering that ALP is an early osteogenic marker, we can postulate either that the peak had already occurred before day 28 or that we are in the presence of the onset of a relatively late one. Nevertheless, values are extremely far from those in osteogenic environment, indicating that the extent of the possible differentiation might be very limited. This hypothesis seems to be supported by the quantification of osteocalcin secretion, where it can be seen that in basic culture no condition appears to support osteogenic differentiation more than the others and values were far from the positive controls in DM. Here, it is worth to notice that cells cultured on $\mathrm{X}_{\mathrm{t}} 50$ films seemed to have secreted more OCN than those on amorphous and maximum crystalline films, although not significantly. The OPN profile is somewhat counterintuitive, as at day 7 cells in basic conditions performed comparably to the osteogenic environment but they outperformed at day 28 , with $\mathrm{X}_{\mathrm{t}} 50$ standing out. Aubin et al. [69] noted that ALP production first increases then decreases when mineralization is in an advanced stage, and that osteopontin should appear prior to osteocalcin, which becomes detectable with mineralization. The results obtained here suggest that the cells cultured in osteogenic conditions are in an advanced stage of the differentiation process, with OCN already present. Instead, considering the lower ALP and osteocalcin levels, cells in PM might be in an earlier osteogenesis phase, when OPN has just started appearing. In general, there is no specific condition outperforming the others although $\mathrm{X}_{\mathrm{t}} 50$ films seem to induce a higher secretion of osteogenesis-related proteins in several conditions but never significantly. Most of the studies that investigated the influence of material stiffness on cell differentiation were based on hydrogels and reported a stiffness range of $1-100 \mathrm{kPa}$ to instruct cell fate $[13,16,46$, 47]. In this research, the surface stiffness of the polymer is far greater than the stiffness of hydrogels and it is plausible that the relative difference between the conditions in PM is too limited to induce different responses between each other. This seems to be confirmed by the culture in osteogenic environment, where the soluble factors pushed the osteogenic differentiation, probably overcoming the variations between the conditions. In fact, Engler et al. [16] showed that hMSCs grown on a osteogenic matrix can be induced by soluble cues to express factors from another lineage, yielding to a "mixed hMSC phenotype".

As crystal formation and growth influences the topography of thermoplastic polymers, the effect of typical annealing conditions in melt-based AM on the surface roughness of PLLA/VE18 films was investigated. In fact, the topography of biomedical materials has been known to influence stem cell differentiation both in 2D $[29,33]$ and $3 \mathrm{D}[5,30,31]$ constructs. As previously described, there were no significant differences in terms of $R_{a}$ between the conditions, although a wide distribution was found for S60 and S80 films. To assess whether these surface features could influence hMSCs fate, cells were cultured for 28 days on films annealed at 60,80 and $100{ }^{\circ} \mathrm{C}$ in unconfined conditions. DNA data indicate that cells adhered and proliferated homogeneously on all films, and appeared to be metabolic active. However, cells cultured in osteogenic conditions showed a slightly higher metabolic activity, probably sign of progressing differentiation as previously mentioned. This seemed to be confirmed by the values for osteogenic markers, which were generally higher in DM than in basic conditions, at both time points. Probably, the relative differences in surface roughness among the conditions was not enough to induce a significant response by one of them, but also the effect of surface cues seemed to be weaker than that by the soluble factors. Nevertheless, considering the surface roughness profiles from the films, the interesting ALP results at day 28 in osteogenic conditions are complicated to be placed in context with previous studies. Neves 
et al. [5] found that the roughest etched scaffolds $\left(R_{\mathrm{a}} \approx 1.06 \mu \mathrm{m}\right)$ induced osteogenic differentiation on hMSCs while Wilson et al. [31] showed higher osteogenic markers in scaffolds with surface roughness lower than $0.227 \mu \mathrm{m}$. Because of the high variability in roughness values for S60 and S80, it does not seem possible to categorize the data into "low" or "high" relative roughness in our study. What we observe is that ALP production is influenced by the overall crystal size distribution rather than the average roughness. In fact, samples annealed at $100{ }^{\circ} \mathrm{C}$ showed a relatively low variability and ALP production more significantly higher than the two other conditions, which did not differ from each other as much. Whether smaller or bigger crystals are favoring osteogenic differentiation, ALP values are affected also by those cells growing on surface portions not inducing osteogenesis, thus fading the effect of those crystals domains influencing cell fate. Results from OPN at day 28 showed comparable values for S80 and S100 over the two media, probably indicating that cells in DM are in the osteoprogenitor phase, when there is ALP expression but uncertain osteopontin secretion [4]. Instead, cells cultured on S60 gave a very marked peak for OPN, suggesting that they might be in a later phase of differentiation when the level of ALP starts to decline and OPN to be observed $[70,71]$. It might be that 660 induced more ALP expression than S100 in a time point earlier than 28 days, which was not considered here. Considering OPN and ALP values together, we hypothesize that $\mathrm{S} 60$ in DM accelerated osteogenic differentiation compared to $\mathrm{S} 100$ while cells cultured on this film appeared to be still in an earlier phase. It is important to note that S60 and S80 films showed roughly the same surface roughness values but different OPN expression. This should not be ascribed to differences in stiffness, as the samples are maximum crystalline and thus they should show the same modulus [53]. Instead, the surface roughness results showed a wider size distribution for S80, indicating the presence of both smaller and bigger crystals compared to S60. Reminding that S100 showed the narrowest crystal size distribution and the highest ALP values at day 28, it appears that extreme roughness values in the obtained range did not particularly favor osteogenesis. In the study of Faia-Torres et al. [29], hMSCs were cultured on PCL substrates where a gradient in surface roughness was induced. It was found that a specific roughness range induced faster osteogenic commitment compared to tissue culture polystyrene. In this work as well, there seems to be an effective size distribution that promotes faster differentiation in osteogenic conditions, corresponding to S60. Wider crystal size distribution means that cells adhered both on very small and very big crystals. Whereas crystals had dimensions outside the effective range, the cells adhering on them did not contribute to the osteogenic signals, reducing the overall expression, as shown by S80 films.

The preliminary assessment of the impact of typical AM annealing conditions on the surface properties of polymer films indicates that stiffness can be controlled in a finer way than roughness. Nevertheless, the latter seemed to affect cell fate more strongly than surface stiffness in the range evaluated in this study. Furthermore, the whole crystal size distribution appeared to play an important role, rather than the average roughness. Our study supports that the thermal history in AM must be carefully considered when extruding polymers with controllable crystallization kinetics, as it can influence surface properties known to impact cell behavior and potentially induce "priming" [72]. In this respect, future studies should also aim at evaluating the effect of long-term cell culture on the surface properties of the substrates. PLLA is a hydrolytically degradable polymer and the degradation process preferentially takes place in the amorphous regions, resulting in an increase in crystallinity [73]. It is reasonable to assume that some conformational modification might occur at the surface, thus influencing cell response to the evolving substrate. In addition, the effect of annealing in 3D should be investigated as well, as more complicated thermal phenomena such as conductive dissipation within the filament and radial trends might appear. In a preliminary test (experimental procedure not described), the incorporation of breaks between subsequent layers deposition showed lower temperature peaks, resulting from greater heat dissipation (Fig. 10, left). Reduced heat accumulation is likely to improve the control over spatial variations in cold crystallization. Figure 10, right, shows the crystallinity over height in a scaffold printed employing a $10 \mathrm{~s}$ break between layers. The 2D WAXD confirmed the achievement of a crystallinity gradient, which suggests that material and scaffold properties can be tuned by carefully controlling the temperature profile during printing. This method could provide a potential simpler approach to induce stem cell differentiation towards the osteogenic lineage compared to the more conventional approaches of creating polymer composite scaffolds [74], despite the use of specific inorganic fillers could still be combined with the control in surface roughness and crystallinity here proposed to further provide the fabricated scaffolds with other biofunctional properties. Examples of further instructive AM scaffolds include bioglasses to stimulate angiogenesis in combination with osteogenesis [75], and antibiotics to prevent possible risks of infections [76], among others.

\section{Conclusions}

This study presents the development of a material system to achieve a surface stiffness range in the order of magnitude of the adult osteochondral region, at body temperature. Furthermore, we report that surface stiffness and surface roughness can be separately influenced by finely control crystallinity formation via thermal annealing typical of melt-based AM. Indentation tests revealed that the polymeric films presented surface stiffness that varied as function of the crystalline fraction, over a range typical of the osteochondral region. Surface roughness showed no variations in average with annealing 

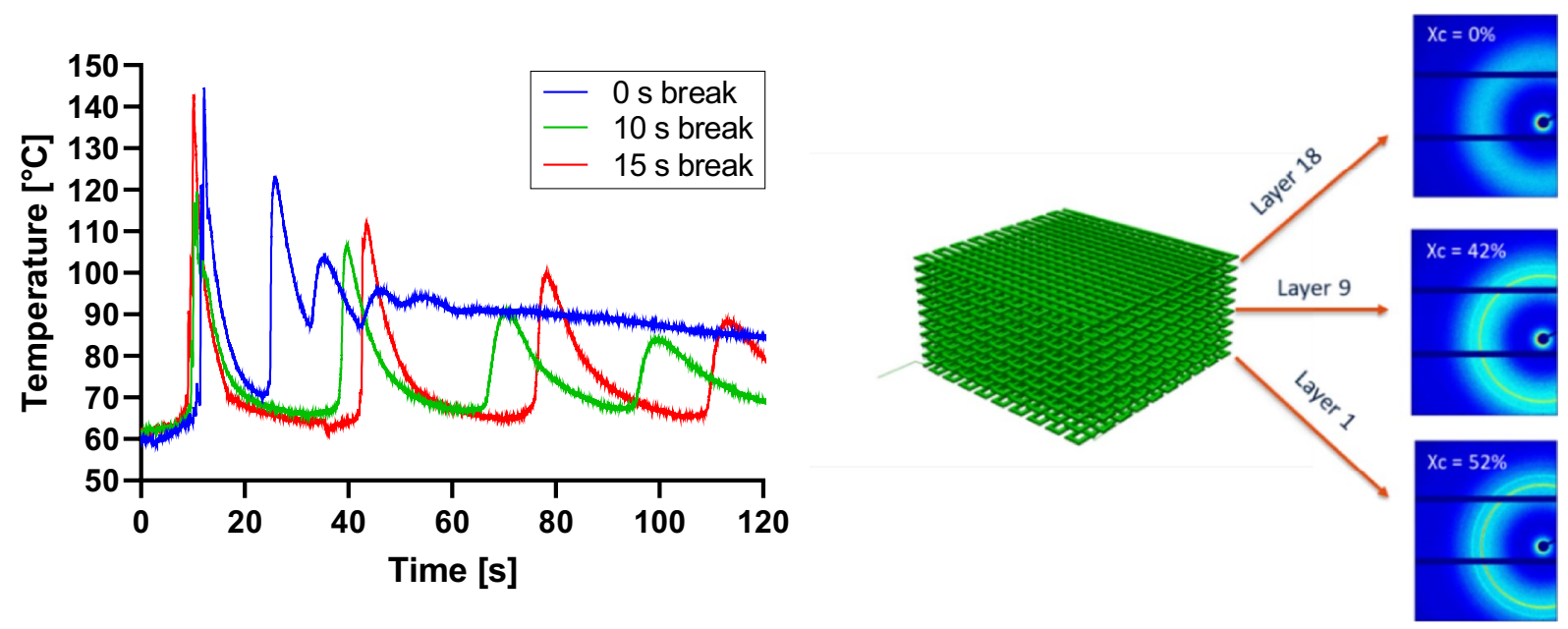

Figure 10: (Left) Temperature profiles of printing scaffolds recorded at the center of the bottom layer at $50 \mathrm{~mm} / \mathrm{s}$ printing speed with breaks of 0,10 and $15 \mathrm{~s}$ after each layer deposition. (Right) Scaffold printed employing a break of $10 \mathrm{~s}$ after the deposition of each layer. 2D WAXD patterns of layer1, 9 and 18 reveal the crystallinity gradient achieved.

temperature, but substantial differences in crystal size distribution. The impact of these two surface properties on hMSCs osteogenic commitment was investigated, showing that cells seemed to respond more sensibly to the crystal size distribution, although only in osteogenic culture conditions, than the achieved stiffness range. This suggests that the impact of thermal history on the properties of thermoplastic polymers should be carefully considered to control cell "priming", in particular when driving cell fate towards other lineages.

\section{Methodology}

\section{Materials}

Poly(L-Lactide), PLLA, with an inherent viscosity midpoint of $1.8 \mathrm{dl} / \mathrm{g}$ (PL18), was kindly provided by Corbion (The Netherlands). Poly(3-HydroxyButurate-co-3-hydroxyValerate), PHBV (Enmat Y1000) was supplied by Helian Polymers. Poly(DiOxanone), PDO, (Resomer $\left.{ }^{\bullet} \mathrm{X} 206 \mathrm{~S}\right)$ and Poly( $\varepsilon$-CaproLactone), PCL $\left(M_{n} 80,000 \mathrm{~g} / \mathrm{mol}\right)$ were purchased from Sigma-Aldrich. Vitamin E (VE) (( \pm )-alpha-Tocopherol, 95\%, synthetic) was supplied by Thermo Fisher Scientific. To prevent hydrolytic degradation under processing conditions, all polymers were dried according to the manufacturer's protocol before any thermal treatment, typically above the glass transition temperature. Silicon wafers were purchased from Si-Mat (Germany).

\section{Material selection}

\section{PLLA plasticization}

Due to the absence of conformational and segmental translational motion the stiffness of polymers below the glass transition temperature $\left(T_{\mathrm{g}}\right)$ is typically 2-3 GPa. Mobilization of the amorphous phase by increasing the temperature above $T_{\mathrm{g}}$ provides a stiffness range from 0.5 to $1000 \mathrm{MPa}$. Within this range the stiffness depends among other parameters largely on crystallinity. In analogy, a reduction of the $T_{\mathrm{g}}$ of PLLA close to or below $37^{\circ} \mathrm{C}$ provides access to the targeted stiffness range. Upon screening potentially biocompatible plasticizers, Vitamin E (VE) was found in our laboratory to plasticize PLA. The polymer was blended with VE using different weight fractions by solutionmixing to detect the minimum weight fraction that lowered $T_{\mathrm{g}}$ below body temperature (from now on, referred to as PLLA/ VE). Briefly, PLLA and VE were dissolved in chloroform at room temperature and stirred for $1 \mathrm{~h}$. The solution was then cast on a glass petri dish and the solvent was evaporated overnight until a film was formed. All the steps were performed away from direct light to prevent degradation of VE. To remove solvent residue, the samples were dried overnight under vacuum at $35^{\circ} \mathrm{C}$.

\section{Thermal analysis}

The thermal properties of PDO, PHBV and PLLA/VE were evaluated with a DSC (Q2000, TA instruments). All samples, $5 \pm 0.5 \mathrm{mg}$, were loaded and sealed in hermetic aluminum pans, and the thermal history was erased by heating above the melting temperature $\left(T_{\mathrm{m}}\right)$ and quenching in dry ice-acetone mixture $\left(-80^{\circ} \mathrm{C}\right)$. The pans were stored at $-30^{\circ} \mathrm{C}$ until analyzed. The tests were run using dry nitrogen as purge gas.

The glass transition temperature $\left(T_{\mathrm{g}}\right)$ of PLLA/VE blends was determined upon heating from 0 to $200^{\circ} \mathrm{C}$ at a rate of $10^{\circ} \mathrm{C} /$ $\mathrm{min}$. The concentration was increased stepwise starting from $5 \mathrm{wt} \%$, to reduce the $T_{\mathrm{g}}$ to $37^{\circ} \mathrm{C}$ while keeping the amount of plasticizer limited. High concentrations of VE could induce 
excessive hydrophobicity of the material surface but also accelerate crystallization [77], limiting the control over the process. The PLLA/VE blend with 18 wt\% VE (from now on, PLLA/ VE18) exhibited a $T_{\mathrm{g}}$ close to $37^{\circ} \mathrm{C}$ at a still relatively limited VE concentration. For this reason, PLLA/VE18 was selected among the PLLA/VE blends for further studies.

To evaluate the absence of cold crystallization at body temperature, which would induce undesired changes in crystallinity and thus surface stiffness, isothermal DSC was run on PHBV, PDO and PLLA/VE blends with suppressed crystallization upon fabrication/cooling. Isothermal DSC was run by loading the pans in the DSC machine, heating them at $30^{\circ} \mathrm{C} / \mathrm{min}$ to $37^{\circ} \mathrm{C}$ and leaving them isothermally for $90 \mathrm{~min}$. Samples were further heated up to $200{ }^{\circ} \mathrm{C}$ at $10^{\circ} \mathrm{C} / \mathrm{min}$ and then cooled down to $25^{\circ} \mathrm{C}$ at the same rate. The thermal transitions of PCL were screened via fast-scanning chip calorimetry (using a Flash DSC2 from Mettler Toledo as crystallization upon cooling cannot be suppressed at the cooling rates accessible in conventional DSC technology. The sample, previously loaded on a ceramic multistar UFH1 chip, and exposed to multiple heating and cooling ramps ranging from -90 to $100{ }^{\circ} \mathrm{C}$ with $3 \mathrm{~s}$ of isothermal periods in between. Whereas the heating rate was kept constant, namely $100{ }^{\circ} \mathrm{C} / \mathrm{s}$, the cooling rates were varied in a range from 1 to $500{ }^{\circ} \mathrm{C} / \mathrm{s}$. The cold crystallization temperature $\left(T_{\mathrm{c}}\right)$ was evaluated form the heating cycles.

\section{Thermal stability}

The rheological behavior of the materials over time was measured with a TA DHR rheometer with a parallel plates configuration ( $25 \mathrm{~mm}$ diameter and gap in the range $0.5-0.7 \mathrm{~mm}$ ). The samples were loaded at $190^{\circ} \mathrm{C}$ and the time between the loading and the start of the test was kept constant between samples. The materials were sheared for $60 \mathrm{~min}$ at $1 \mathrm{rad} / \mathrm{s}$ and $1 \%$ strain. As none of the pure polymers showed sufficiently low $T_{\mathrm{g}}$ and stability of the suppressed crystallinity at body temperature, only the PLLA/VE18 sample was considered suitable for further studies.

\section{Surface stiffness}

\section{Isothermal crystallization of PLLA/VE18}

The isothermal crystallization behavior was evaluated via DSC. Beforehand, an amorphous sample was prepared by melting the solution-cast film between two silicon wafers at $180^{\circ} \mathrm{C}$ for $1 \mathrm{~min}$ and then rapidly quenched under running tap water. This was confirmed by 2D WAXD (data included in supporting information, Fig. S1). The sample was sealed in a hermetic aluminum pan, heated to $60^{\circ} \mathrm{C}$ at $30^{\circ} \mathrm{C} / \mathrm{min}$ in a TA instruments Q2000 DSC and kept isothermally for $1 \mathrm{~h}$. Relative crystallinities of 0,50 and $100 \%$ (with respect to the maximum attainable crystallinity for this specific material) were selected for the following studies. From now on, these will be referred to as $\mathrm{X}_{t} 0$, $\mathrm{X}_{\mathrm{t}} 50$ and $\mathrm{X}_{\mathrm{t}} 100$, respectively.

\section{Annealing}

Solution-cast films were made amorphous as previously described. These were then crystallized at $60^{\circ} \mathrm{C}$ in between two silicon wafers, in air, for 45 and $240 s$ to achieve $\mathrm{X}_{t} 50$ and $\mathrm{X}_{\mathrm{t}} 100$, respectively. The films were then rapidly quenched under running tap water.

\section{Mechanical characterization}

PLLA/VE18 films were mechanically tested to evaluate the shear modulus $G^{\prime}$ and the surface stiffness.

An Anton Paar MCR 302 was used to record the shear modulus by dynamic mechanical testing in torsion. Samples were subjected to a strain of $0.01 \%$ at a frequency of $1 \mathrm{~Hz}$. Surface stiffness was evaluated by indentation with a Nanoindenter XP (MTS Systems, USA). Samples were tested with a $2 \mathrm{~mm}$ cylindrical flat-ended indenter in controlled displacement mode, with a $3 \mu \mathrm{m}$ displacement. Five measurements per sample were performed, at different locations. Force as a function of displacement was recorded during the loading and unloading cycles.

\section{Scaffold printing}

A 3Devo single screw extruder was used to prepare a PLLA/ VE18 filament by melt extrusion at $190^{\circ} \mathrm{C}$, with a mean diameter of $2.85 \mathrm{~mm}$. Thereafter, an Ultimaker $2+$ filament printer was used to fabricate the scaffolds at a nozzle temperature of $190^{\circ} \mathrm{C}$, a build plate temperature of $60^{\circ} \mathrm{C}$ and a deposition speed of $50 \mathrm{~mm} / \mathrm{s}$. The samples consisted of 18 layers with a layer height of $0.4 \mathrm{~mm}$, an infill of $50 \%$ and a deposition patter of $0^{\circ} / 90^{\circ}$, for total dimensions of $20 \times 20 \times 7.2 \mathrm{~mm}^{3}$. To obtain a crystallinity gradient along the vertical axis, where the highest value could be found in the bottom layer, the printing speed was adjusted such that maximum crystallinity could be attained within the part building time. The time to achieve $100 \%$ relative crystallinity in the bottom layer was estimated from the isothermal crystallization measurements of PLLA/VE18 at $60^{\circ} \mathrm{C}$.

Additionally, temperature profiling of the bottom layer was performed to ensure that proper heat dissipation along the building height would take place. This would allow the formation of a complete gradient in crystallinity. To this end, the temperature history of the first deposited layer was recorded with varying time intervals between the depositions of consecutive layers. A $0.15 \mathrm{~mm}$ K-type thermocouple was placed in the middle of the bottom layer and data were recorded with a DataQ DI718 data acquisition read-out system with $1 \mathrm{kHz}$ sampling frequency. 


\section{Surface roughness}

\section{Annealing}

Solution-cast films were made amorphous ( $0 \%$ crystallinity) as previously described. These were all around $25 \mathrm{~mm}$ in radius and $0.4 \mathrm{~mm}$ in thickness. The films were then fixed on a silicon wafer and annealed at 60,80 or $100^{\circ} \mathrm{C}$ (referred to as S60, S80 and S100) for $240 \mathrm{~s}$ to achieve maximum crystallinity. The top surface was allowed to crystallize unconfined. The films were then rapidly quenched.

\section{Surface roughness measurement}

A Keyence VK-X250 3D Laser Scanning Microscope was used to analyze the surface roughness of the films. Measurements were performed at a 20X magnification in surface profile mode. Data was analyzed using the VK Analyzer software (version 2.5.0.1, Keyence, Japan) and the arithmetic average roughness ( $\mathrm{Ra}$ ) was obtained.

\section{Contact angle measurement}

For static contact angle measurements, films were preliminarily incubated overnight at $37^{\circ} \mathrm{C}$ in a solution of $1 \mathrm{mg} / \mathrm{ml}$ collagen type I from rat tail (Corning) in $0.02 \mathrm{~N}$ acetic acid. Collagen was used to further improve cell adhesion in cell culture studies. The next day, they were washed with sterile demineralized $\mathrm{H}_{2} \mathrm{O}$ and allowed to dry in air. Contact angle measurements with $\mathrm{dH}_{2} \mathrm{O}$ were performed by the sessile drop technique using an optical contact angle device DSA25 (KRÜSS GmbH) equipped with an electronic syringe unit (OCA15, Dataphysics, Germany). The drop analysis and contact angle measurements were evaluated with the software DSA4, by applying the Young-Laplace method.

\section{Cell seeding and culture}

\section{Cell expansion}

hMSCs isolated from bone marrow were purchased from Lonza (Donor 19TL029340, male, age 24). hMSCs and the osteosarcoma cell line MG-63 (ATCC) were plated at $1000 \mathrm{cells} / \mathrm{cm}^{2}$ in tissue culture flasks and cultured at $37^{\circ} \mathrm{C} / 5 \% \mathrm{CO}_{2}$ in basic medium (BM), consisting of a-MEM with Glutamax and no nucleosides (Gibco) supplemented with 10 vol\% FBS (SigmaAldrich), until 80\% confluence.

\section{Cell seeding and culture}

Discs of $13 \mathrm{~mm}$ in diameter were punched from $\mathrm{X}_{t} 0$ films. These were then sterilized with exposure to UV light (365 nm) in a CL-1000 Ultraviolet Crosslinker, 20 min per side.

MG-63 cells were used to preliminarily assess any potential toxic effect of VE. Trypsinized cells were centrifuged at
$500 \mathrm{rcf}$ for $5 \mathrm{~min}$ and then resuspended in BM at a density of 50,000 cells $/ \mathrm{ml}$. 25,000 cells $/ \mathrm{cm}^{2}$ were seeded in the wells of a 24-well plate and allowed to attach overnight. The next day (day 0 ), the medium was replaced with proliferation medium (PM, BM supplemented with penicillin $(100 \mathrm{U} / \mathrm{ml})$, streptomycin $(100 \mu \mathrm{g} / \mathrm{ml})$ (Fisher-Scientific) and $200 \mu \mathrm{M} \mathrm{L}$-ascorbic acid 2-phosphate (Sigma-Aldrich). Transwells ( $8 \mu \mathrm{m}$ polycarbonate pore size, Corning) containing the amorphous PLLA/ VE18 films were placed inside the wells. The metabolic activity and DNA content of the cultured cells was analyzed at day 1 and 3 , with no medium refresh.

To evaluate the seeding efficiency, amorphous films were either plasma treated followed by overnight incubation in BM supplemented with penicillin $(100 \mathrm{U} / \mathrm{ml})$ and streptomycin $(100 \mu \mathrm{g} / \mathrm{ml})$ (Fisher-Scientific) or coated with collagen. To plasma treat the films, these were first sealed in plasma sterilization pouches. The pouches were then placed in the chamber of a plasma cleaner (Femto PCCE) and exposed for 2 min to oxygen plasma, at a pressure of $0.53 \mathrm{mbar}$ and $100 \mathrm{~W}$ of power [45]. The collagen coating was applied by incubating the films overnight at $37^{\circ} \mathrm{C}$ in a solution of $1 \mathrm{mg} / \mathrm{ml}$ collagen type I from rat tail (Corning) in $0.02 \mathrm{~N}$ acetic acid. Before seeding, all films were dried on top of a sterile filter paper and then placed in the wells of non-threated 24 well plate. Trypsinized MG-63 cells were centrifuged at $500 \mathrm{rcf}$ for $5 \mathrm{~min}$ and then resuspended in $\mathrm{PM}$ at a density of 50,000 cells/ml. The cell suspensions $(1 \mathrm{ml})$ was pipetted on top of each film and the plate was incubated at $37^{\circ} \mathrm{C} / 5 \% \mathrm{CO}_{2}$. The culture was observed after $24 \mathrm{~h}$.

To investigate any osteogenic effect induced by the different stiffnesses, films were collagen-coated as previously described. The next day, hMSCs (passage 4) were trypsinized and centrifuged for $5 \mathrm{~min}$ at $500 \mathrm{rcf}$. The cells were then resuspended at a density of 50,000 cells per $1 \mathrm{ml}$ in PM. The cell suspensions $(1 \mathrm{ml})$ were pipetted on top of each film and the plate was incubated at $37{ }^{\circ} \mathrm{C} / 5 \% \mathrm{CO}_{2}$. The medium was replaced after $24 \mathrm{~h}$ and every two or three days from then on. After 7 days (day 0), scaffolds were cultured for another 28 days in PM or mineralization media [DM, PM supplemented with $10 \mathrm{nM}$ dexamethasone (Sigma-Aldrich) and $10 \mathrm{mM} \beta$-glycerophosphate (Sigma-Aldrich)]. The medium was replaced every two or three days. The culture was analyzed for metabolic activity, alkaline phosphatase (ALP) activity, DNA content both at day 7 and 35, while for osteocalcin and osteopontin production and mineralization at day 28 .

\section{Biochemical assays \\ Metabolic activity}

PrestoBlue assay (Thermo Fisher Scientific) was used to quantify cell metabolic activity. Briefly, cell culture medium in sample plates 
was replaced with medium containing $10 \mathrm{v} / \mathrm{v} \%$ PrestoBlue reagent and the sample plates were incubated in the dark at $37^{\circ} \mathrm{C}$ for $1 \mathrm{~h}$. A volume of $100 \mu \mathrm{l}$ was transferred to a black 96 well plate and fluorescence was measured at $590 \mathrm{~nm}$ with a plate reader (CLARIOstar ${ }^{\oplus}$ BMG Labtech).

\section{ALP assay}

The scaffolds were washed $3 \times$ with PBS and freeze-thawed 3 times. Samples were then incubated for $1 \mathrm{~h}$ at RT in a cell lysis buffer composed of $0.1 \mathrm{M} \mathrm{KH}_{2} \mathrm{PO}_{4}, 0.1 \mathrm{M} \mathrm{K}_{2} \mathrm{HPO}_{4}$ and $0.1 \mathrm{vol} \%$ Triton $\mathrm{X}-100$, at $\mathrm{pH}$ 7.8. $10 \mu \mathrm{l}$ of cell lysate were collected and $40 \mu \mathrm{l}$ of the chemiluminescent substrate for alkaline phosphatase (CDP-star, Roche) were added. Luminescence (emission $=470 \mathrm{~nm}$ ) was measured after $15 \mathrm{~min}$ incubation, using a spectrophotometer (CLARIOstar ${ }^{\oplus}$, BMG Labtech). Remaining cell lysates were used for DNA quantification. ALP values were normalized to the DNA content.

\section{DNA assay}

CyQUANT Cell Proliferation Assay Kit (Thermo Fisher Scientific) was used to quantify the DNA. Samples from ALP assay were first incubated overnight at $56^{\circ} \mathrm{C}$ in $1 \mathrm{mg} / \mathrm{ml}$ Proteinase $\mathrm{K}$ (SigmaAldrich) in Tris/EDTA buffer and then freeze-thawed three more times. Subsequently, to degrade the cellular RNA, the lysate was incubated $1 \mathrm{~h}$ at RT in a buffer composed of 1:500 RNase A in the cell lysis buffer from the kit diluted $20 \times$ in distilled water $\left(\mathrm{dH}_{2} \mathrm{O}\right)$. The samples were then incubated for $15 \mathrm{~min}$ in the fluorescent dye provided by the kit (1:1) for $15 \mathrm{~min}$ and fluorescence was measured $($ emission$/$ excitation $=520 / 480 \mathrm{~nm}$ ) with a spectrophotometer. DNA concentrations were calculated from a DNA standard curve.

\section{Elisa}

The production of osteocalcin (OCN) and osteopontin (OPN) were quantified using ELISA kits (ab270202 and ab192143 respectively, Abcam) according to the manufacturer's instructions. Briefly, at the specified time points, the supernatant from the scaffolds was collected and the protein content was quantified using the ELISA kits. The same samples were used for both assays.

\section{Cell imaging}

\section{Confocal fluorescence microscopy}

Films seeded with hMSCs were fixed in $4 \%$ paraformaldehyde and incubated for $30 \mathrm{~min}$ in Triton-X 100 (0.1\% v\%). A Sudan black solution was added for $60 \mathrm{~min}$ to dampen the biomaterial autofluorescence. Then, cell cytoskeleton were stained with 488 Alexa Fluor Phalloidin (Thermo Fisher Scientific, 1:75 dilution in PBS, $1 \mathrm{~h}$ at RT) and nuclei with DAPI ( $0.1 \mu \mathrm{g} /$ $\mathrm{mL}$ in PBS, $15 \mathrm{~min}$ ). Confocal laser scanning microscopy was performed with a tandem confocal system (Leica TCS SP8 STED), equipped with a white light laser (WLL). Samples were excited with the dye specific wavelengths and emission was detected with HyD detectors. For optimal visualization, phalloidin was colored in green and DAPI in blue.

\section{Scanning electron microscopy}

HMSCs cultured on the polymeric films were fixed in $4 \%$ paraformaldehyde, and subsequently dehydrated using a graded ethanol series $(30,50,70,80,90,96,3 \times 100 \%)$. The films were washed for $30 \mathrm{~min}$ in each solution, after which the ethanol was evaporated in a critical point dryer (Leica EM CPD300) to preserve the surface details of the cultured cells. Finally, a thin layer of gold coating was applied (Quotum Technologies SC7620 Mini Sputter Coater) before imaging them on the scanning electron microscope (Jeol JSM-IT200). The images were captured at magnifications of $\times 130, \times 400$ and $\times 800$, at an accelerating voltage of $10 \mathrm{kV}$ and working distance of $10 \mathrm{~mm}$.

\section{Statistical analysis}

Statistical analyses were performed using GraphPad Prism software. For contact angle, surface stiffness and roughness measurements, a one-way ANOVA test was used. For the transwell study, an unpaired $t$ test was used to compare between the conditions at the same time point and between the time points of the same condition. For the seeding efficiency study, a one-way ANOVA with Tukey's post-hoc test was used. Statistically significant differences are marked with ${ }^{\star} p<0.05$, ${ }^{* *} p<0.01$ or ${ }^{* *} p<0.001$. Experiments were repeated at least 3 times.

For the osteogenic studies, statistical significance was assessed with a one-way ANOVA test with Tukey's post-hoc test for comparison among the conditions in the same medium (surface stiffness or roughness) while with an unpaired $t$ test when comparing the same condition in the two media. Statistically significant differences are marked with ${ }^{\star} p<0.05,{ }^{* *} p<0.01$ or ${ }^{* * *} p<0.001$ when comparing the effect of different surface stiffness or roughness on cells cultured in the same cell medium and ${ }^{\S} p<0.05,{ }^{\S \S} p<0.01$ or ${ }^{\S \S} p<0.001$ when comparing the effect of different media on cells cultured on films with the same surface stiffness or roughness. Samples in all experiments were in triplicates $(n=3)$.

\section{Acknowledgments}

Some of the materials were kindly provided by Corbion (The Netherlands). This work was financed by Brightlands Material Center and by the Dutch Province of Limburg. This study was 
also supported by the 4 NanoEARDRM project, funded under the frame of EuroNanoMed III, an ERA-NET Cofund scheme of the Horizon 2020 Research and Innovation Framework Programme of the European Commission.

\section{Data availlability}

Data will be made available upon reasonable request.

\section{Declarations}

Conflict of interest There are no conflict of interests to be declared by the authors.

\section{Open Access}

This article is licensed under a Creative Commons Attribution 4.0 International License, which permits use, sharing, adaptation, distribution and reproduction in any medium or format, as long as you give appropriate credit to the original author(s) and the source, provide a link to the Creative Commons licence, and indicate if changes were made. The images or other third party material in this article are included in the article's Creative Commons licence, unless indicated otherwise in a credit line to the material. If material is not included in the article's Creative Commons licence and your intended use is not permitted by statutory regulation or exceeds the permitted use, you will need to obtain permission directly from the copyright holder. To view a copy of this licence, visit http://creativecommons.org/ licenses/by/4.0/.

\section{Supplementary Information}

The online version contains supplementary material available at https://doi.org/10.1557/s43578-021-00403-2.

\section{References}

1. C. Mota, D. Puppi, F. Chiellini, E. Chiellini, Additive manufacturing techniques for the production of tissue engineering constructs. J. Tissue Eng. Regen. Med. 9, 174-190 (2015)

2. S. Camarero-Espinosa, C. Tomasina, A.R. Calore, L. Moroni, Additive manufactured, highly resilient, elastic, and biodegradable poly(ester)urethane scaffolds with chondroinductive properties for cartilage tissue engineering. Mater. Today Biol 6, 100051 (2020)

3. A.R. Calore et al. Chapter 7 Thermoplastics for tissue engineering. in Computer-Aided Tissue Engineering, ed. A. Rainer, L. Moroni), pp. 75-99 (2021)

4. C.A. Van Blitterswijk, J. De Boer, Tissue Engineering, 2nd edn. (Elsevier, Amsterdam, 2014). https://doi.org/10.1016/ C2013-0-00564-6
5. G. Kumar, M.S. Waters, T.M. Farooque, M.F. Young, C.G. Simon, Freeform fabricated scaffolds with roughened struts that enhance both stem cell proliferation and differentiation by controlling cell shape. Biomaterials 33, 4022-4030 (2012)

6. J.C. Middleton, A.J. Tipton, Synthetic biodegradable polymers as orthopedic devices. Biomaterials 21, 2335-2346 (2000)

7. D.W. Hutmacher, Scaffold design and fabrication technologies for engineering tissues-state of the art and future perspectives. J. Biomater. Sci. Polym. Ed. 12, 107-124 (2001)

8. T. Miyata, T. Masuko, Crystallization behaviour of poly $(\mathrm{L}-$ lactide). Polymer 39, 5515-5521 (1998)

9. G. Perego, G.D. Cella, C. Bastioli, Effect of molecular weight and crystallinity on poly(lactic acid) mechanical properties. J. Appl. Polym. Sci. 59, 37-43 (1996)

10. F.W. Billmeyer. Textbook of Polymer Science. Kobunshi vol. 12 (1963)

11. M. Cocca, M.L. Di Lorenzo, M. Malinconico, V. Frezza, Influence of crystal polymorphism on mechanical and barrier properties of poly(l-lactic acid). Eur. Polym. J. 47, 1073-1080 (2011)

12. H.F. Brinson, L.C. Brinson, Polymer Engineering Science and Viscoelasticity: An Introduction (. Springer, New York, 2015). https:// doi.org/10.1007/978-1-4899-7485-3

13. N. Huebsch et al., Harnessing traction-mediated manipulation of the cell/matrix interface to control stem-cell fate. Nat. Mater. $\mathbf{9}$, 518-526 (2010)

14. W.J. Hendrikson, J. Rouwkema, C.A. Van Blitterswijk, L. Moroni, Influence of PCL molecular weight on mesenchymal stromal cell differentiation. RSC Adv. 5, 54510-54516 (2015)

15. J.H. Wen et al., Interplay of matrix stiffness and protein tethering in stem cell differentiation. Nat. Mater. 13, 979-987 (2014)

16. A.J. Engler, S. Sen, H.L. Sweeney, D.E. Discher, Matrix elasticity directs stem cell lineage specification. Cell 126, 677-689 (2006)

17. T. Yeung et al., Effects of substrate stiffness on cell morphology, cytoskeletal structure, and adhesion. Cell Motil. Cytoskelet. 60, 24-34 (2005)

18. A. Zemel, F. Rehfeldt, A.E.X. Brown, D.E. Discher, S.A. Safran, Cell shape, spreading symmetry, and the polarization of stressfibers in cells. J. Phys. Condens. Matter 22, 194110 (2010)

19. L. MacQueen, Y. Sun, C.A. Simmons, Mesenchymal stem cell mechanobiology and emerging experimental platforms. J. R. Soc. Interface 10, 20130179 (2013)

20. K. Chatterjee et al., The effect of 3D hydrogel scaffold modulus on osteoblast differentiation and mineralization revealed by combinatorial screening. Biomaterials 31, 5051-5062 (2010)

21. J.S. Park et al., The effect of matrix stiffness on the differentiation of mesenchymal stem cells in response to TGF- $\beta$. Biomaterials 32, 3921-3930 (2011)

22. A. Di Luca et al., Surface energy and stiffness discrete gradients in additive manufactured scaffolds for osteochondral regeneration. Biofabrication 8, 015014 (2016) 
23. K.A. Athanasiou, C.-F. Zhu, D.R. Lanctot, C.M. Agrawal, X. Wang, Fundamentals of biomechanics in tissue engineering of bone. Tissue Eng. 6, 361-381 (2000)

24. A. Di Luca, C. Van Blitterswijk, L. Moroni, The osteochondral interface as a gradient tissue: From development to the fabrication of gradient scaffolds for regenerative medicine. Birth Defects Res. Part C 105, 34-52 (2015)

25. S. Camarero-Espinosa, A.R. Calore, A. Wilbers, J. Harings, L. Moroni, Additive manufacturing of an elastic poly(ester) urethane for cartilage tissue engineering. Acta Biomater. 102, 192-204 (2020)

26. A. Larena, G. Pinto, The effect of surface roughness and crystallinity on the light scattering of polyethylene tubular blown films. Polym. Eng. Sci. 33, 742-747 (1993)

27. N.R. Washburn, K.M. Yamada, C.G. Simon, S.B. Kennedy, E.J. Amis, High-throughput investigation of osteoblast response to polymer crystallinity: influence of nanometer-scale roughness on proliferation. Biomaterials 25, 1215-1224 (2004)

28. F. Guilak et al., Control of stem cell fate by physical interactions with the extracellular matrix. Cell Stem Cell 5, 17-26 (2009)

29. A.B. Faia-Torres et al., Osteogenic differentiation of human mesenchymal stem cells in the absence of osteogenic supplements: a surface-roughness gradient study. Acta Biomater. 28, 64-75 (2015)

30. H. Chen et al., Tailoring surface nanoroughness of electrospun scaffolds for skeletal tissue engineering. Acta Biomater. 59, 82-93 (2017)

31. S.C. Neves et al., Additive manufactured polymeric 3D scaffolds with tailored surface topography influence mesenchymal stromal cells activity. Biofabrication 8, 025012 (2016)

32. C.J. Wilson, R.E. Clegg, D.I. Leavesley, M.J. Pearcy, Mediation of biomaterial-cell interactions by adsorbed proteins: a review. Tissue Eng. 11, 1-18 (2005)

33. G.B. Schneider, R. Zaharias, D. Seabold, J. Keller, C. Stanford, Differentiation of preosteoblasts is affected by implant surface microtopographies. J. Biomed. Mater. Res. Part A 69, 462-468 (2004)

34. V. Srinivas, C.S.J. van Hooy-Corstjens, J.A.W. Harings, Correlating molecular and crystallization dynamics to macroscopic fusion and thermodynamic stability in fused deposition modeling; a model study on polylactides. Polymer 142, 348-355 (2018)

35. P.F. Costa et al., Additive manufacturing of scaffolds with dexamethasone controlled release for enhanced bone regeneration. Int. J. Pharm. 496, 541-550 (2015)

36. B.P. Hung et al., Three-dimensional printing of bone extracellular matrix for craniofacial regeneration. ACS Biomater. Sci. Eng. 2, 1806-1816 (2016)
37. L.R. Jaidev, K. Chatterjee, Surface functionalization of 3D printed polymer scaffolds to augment stem cell response. Mater. Des. 161, 44-54 (2019)

38. S. Li, Y. Xu, J. Yu, M.L. Becker, Enhanced osteogenic activity of poly(ester urea) scaffolds using facile post-3D printing peptide functionalization strategies. Biomaterials 141, 176-187 (2017)

39. A. Di Luca et al., Toward mimicking the bone structure: design of novel hierarchical scaffolds with a tailored radial porosity gradient. Biofabrication 8, 045007 (2016)

40. R. Langer, J.P. Vacanti, Tissue engineering. Science (1993). https://doi.org/10.1126/science.8493529

41. M.A. Woodruff, D.W. Hutmacher, The return of a forgotten polymer-Polycaprolactone in the 21st century. Prog. Polym. Sci. 35, 1217-1256 (2010)

42. E. Reboul, Vitamin e bioavailability: mechanisms of intestinal absorption in the spotlight. Antioxidants 6, 95 (2017)

43. G.M. Pharr, W.C. Oliver, Measurement of thin film mechanical properties using nanoindentation. Mrs Bull. (1992). https:// doi.org/10.1557/S0883769400041634

44. K. Tsougeni, A. Tserepi, G. Boulousis, V. Constantoudis, E. Gogolides, Control of nanotexture and wetting properties of polydimethylsiloxane from very hydrophobic to superhydrophobic by plasma processing. Plasma Process. Polym. 4, 398-405 (2007)

45. J. Yang, J. Bei, S. Wang, Enhanced cell affinity of poly (D, L-lactide) by combining plasma treatment with collagen anchorage. Biomaterials 23, 2607-2614 (2002)

46. O. Chaudhuri et al., Substrate stress relaxation regulates cell spreading. Nat. Commun. 6, 1-7 (2015)

47. N.S. Hwang, S. Varghese, H. Li, J. Elisseeff, Regulation of osteogenic and chondrogenic differentiation of mesenchymal stem cells in PEG-ECM hydrogels. Cell Tissue Res. 344, 499-509 (2011)

48. V. Bernardo, G.M. Luz, N.M. Alves, J.F. Mano, Cell behaviour in new poly(l-lactic acid) films with crystallinity gradients. Mater. Lett. 87, 105-108 (2012)

49. M. Niaounakis, Biopolymers: processing and products. Biopolymers (2014). https://doi.org/10.1016/C2013-0-09982-3

50. J.E. Mark, Physical Properties of Polymers Handbook, vol. 1076 (Springer, New York, 2007)

51. V. Srinivas, Timing of interfacial diffusion and (stereo) crystallization to tailor mechanical properties of additively manufactured poly(lactides). (2020).

52. Gleadall, A. Mechanical properties of biodegradable polymers for medical applications. in Modelling Degradation of Bioresorbable Polymeric Medical Devices (Elsevier Ltd, 2015), pp. 163-199. https://doi.org/10.1533/9781782420255.2.163.

53. H. Tsuji, Y. Ikada, Properties and morphologies of poly(L-lactide): 1 . Annealing condition ts on properties and morphologies of poly(L-lactide). Polymer 36, 2709-2716 (1995) 
54. L. Li, Analysis and Fabrication of FDM Prototypes with Locally Controlled Properties. (2002)

55. E. Zhmayev, H. Zhou, Y.L. Joo, Modeling of non-isothermal polymer jets in melt electrospinning. J. Nonnewton. Fluid Mech. 153, 95-108 (2008)

56. B. Wunderlich, Macromolecular Physics, Crystal Nucleation, Growth, Annealing, vol. 2 (Academic Press Inc., New York, 1976)

57. R.D. Sudduth, P. Kyarala, Q. Sheng, A comparison of induction time and crystallization rate for syndiotactic polystyrene. Polym. Eng. Sci. 42, 694-706 (2002)

58. G. Wolansky, A. Marmur, The actual contact angle on a heterogeneous rough surface in three dimensions. Langmuir 14, 5292-5297 (1998)

59. Y. Tamada, Y. Ikada, Effect of preadsorbed proteins on cell adhesion to polymer surfaces. J. Colloid Interface Sci. 155, 334-339 (1993)

60. S.K. Misra et al., Incorporation of vitamin $\mathrm{E}$ in poly(3hydroxybutyrate)/Bioglass composite films: effect on surface properties and cell attachment. J. R. Soc. Interface 6, 401-409 (2009)

61. F. Renò, V. Aina, S. Gatti, M. Cannas, Effect of vitamin E addition to poly $(\mathrm{d}, \mathrm{l})$-lactic acid on surface properties and osteoblast behaviour. Biomaterials 26, 5594-5599 (2005)

62. B. Trappmann et al., Extracellular-matrix tethering regulates stem-cell fate. Nat. Mater. 11, 642-649 (2012)

63. C. Storm, J.J. Pastore, F.C. MacKintosh, T.C. Lubensky, P.A. Janmey, Nonlinear elasticity in biological gels. Nature 435, 191-194 (2005)

64. K.J. Langenbach, J.T. Elliott, A. Tona, D. McDaniel, A.L. Plant, Thin films of Type 1 collagen for cell by cell analysis of morphology and tenascin-C promoter activity. BMC Biotechnol. 6, 14 (2006)

65. J. Qu, B. Chehroudi, D.M. Brunette, The use of micromachined surfaces to investigate the cell behavioural factors essential to osseointegration. Oral Dis. 2, 102-115 (1996)
66. Y. Wan et al., Adhesion and proliferation of OCT-1 osteoblastlike cells on micro- and nano-scale topography structured poly(L-lactide). Biomaterials 26, 4453-4459 (2005)

67. K. Helm et al., In vitro cell death discrimination and screening method by simple and cost-effective viability analysis. Cell. Physiol. Biochem. 41, 1011-1019 (2017)

68. N. Shyh-Chang, H.H. Ng, The metabolic programming of stem cells. Genes Dev. 31, 336-346 (2017)

69. J.E. Aubin, Advances in the osteoblast lineage. Biochem. Cell Biol. 76, 899-910 (1998)

70. G.S. Stein, J.B. Lian, T.A. Owen, Relationship of cell growth to the regulation of tissue-specific gene expression during osteoblast differentiation. FASEB J. 4, 3111-3123 (1990)

71. J.E. Aubin, Regulation of osteoblast formation and function. Rev. Endocr. Metab. Disord. 2, 81-94 (2001)

72. C. Yang, M.W. Tibbitt, L. Basta, K.S. Anseth, Mechanical memory and dosing influence stem cell fate. Nat. Mater. 13, 645-652 (2014)

73. S. Li, H. Garreau, M. Vert, Structure-property relationships in the case of the degradation of massive poly( $\alpha$-hydroxy acids) in aqueous media - Part 3 Influence of the morphology of poly(1lactic acid). J. Mater. Sci. Mater. Med. 1, 198-206 (1990)

74. O. Bas et al., Tuning mechanical reinforcement and bioactivity of 3D printed ternary nanocomposites by interfacial peptidepolymer conjugates. Biofabrication 11, 035028 (2019)

75. T. Distler et al., Polymer-bioactive glass composite filaments for 3D scaffold manufacturing by fused deposition modeling: fabrication and characterization. Front. Bioeng. Biotechnol. 8, 552 (2020)

76. M. Cámara-Torres et al., 3D additive manufactured composite scaffolds with antibiotic-loaded lamellar fillers for bone infection prevention and tissue regeneration. Bioact. Mater. 6, 1073-1082 (2021)

77. J.-F. Agassant, P. Avenas, P.J. Carreau, B. Vergnes, M. Vincent, Polymer Processing. Polymer vol. 33 (Carl Hanser Verlag GmbH \& Co. KG, 2017). 